\title{
119Sn MAS NMR Study of Probe Molecules Interaction with Sn-BEA: The Origin of Penta- and Hexacoordinated Tin Formation
}

\author{
Yakimov, Alexander V.; G. Kolyagin, Yury; Tolborg, Søren; Vennestrøm, Peter N. R.; Ivanova, Irina I.
}

Published in:

The Journal of Physical Chemistry Part C: Nanomaterials, Interfaces and Hard Matter

Link to article, DOI:

10.1021/acs.jpcc.6b09999

Publication date:

2016

Document Version

Peer reviewed version

Link back to DTU Orbit

Citation (APA):

Yakimov, A. V., G. Kolyagin, Y., Tolborg, S., Vennestrøm, P. N. R., \& Ivanova, I. I. (2016). 119Sn MAS NMR Study of Probe Molecules Interaction with Sn-BEA: The Origin of Penta- and Hexacoordinated Tin Formation. The Journal of Physical Chemistry Part C: Nanomaterials, Interfaces and Hard Matter, 120(49), 28083-28092. https://doi.org/10.1021/acs.jpcc.6b09999

\section{General rights}

Copyright and moral rights for the publications made accessible in the public portal are retained by the authors and/or other copyright owners and it is a condition of accessing publications that users recognise and abide by the legal requirements associated with these rights.

- Users may download and print one copy of any publication from the public portal for the purpose of private study or research.

- You may not further distribute the material or use it for any profit-making activity or commercial gain

- You may freely distribute the URL identifying the publication in the public portal 

BEA: The Origin of Penta- and Hexacoordinated Tin Formation

Alexander Vyacheslavovich Yakimov, Yury G. Kolyagin, Søren

Tolborg, Peter N. R. Vennestrøm, and Irina Igorevna Ivanova

J. Phys. Chem. C, Just Accepted Manuscript • DOI: 10.1021/acs.jpcc.6b09999 • Publication Date (Web): 21 Nov 2016

Downloaded from http://pubs.acs.org on December 1, 2016

\section{Just Accepted}

"Just Accepted" manuscripts have been peer-reviewed and accepted for publication. They are posted online prior to technical editing, formatting for publication and author proofing. The American Chemical Society provides "Just Accepted" as a free service to the research community to expedite the dissemination of scientific material as soon as possible after acceptance. "Just Accepted" manuscripts appear in full in PDF format accompanied by an HTML abstract. "Just Accepted" manuscripts have been fully peer reviewed, but should not be considered the official version of record. They are accessible to all readers and citable by the Digital Object Identifier (DOI®). "Just Accepted" is an optional service offered to authors. Therefore, the "Just Accepted" Web site may not include all articles that will be published in the journal. After a manuscript is technically edited and formatted, it will be removed from the "Just Accepted" Web site and published as an ASAP article. Note that technical editing may introduce minor changes to the manuscript text and/or graphics which could affect content, and all legal disclaimers and ethical guidelines that apply to the journal pertain. ACS cannot be held responsible for errors or consequences arising from the use of information contained in these "Just Accepted" manuscripts. 


\title{
Interaction with Sn-BEA: the Origin of Penta- and
}

\section{Hexacoordinated Tin Formation}

\author{
Alexander V. Yakimov ${ }^{a}$, Yury G. Kolyagin ${ }^{a, b}$, Søren Tolborg ${ }^{c, d}$, Peter N. R. Vennestrøm ${ }^{c}$, Irina I. \\ Ivanova*a,b \\ ${ }^{a}$ Department of Chemistry, Lomonosov Moscow State University, Leninskie gory 1, Moscow, \\ Russia. \\ ${ }^{\mathrm{b}}$ A.V. Topchiev Institute of Petrochemical Synthesis RAS, Moscow, Russia. \\ ${ }^{c}$ Haldor Topsøe A/S, Haldor Topsøes Allé 1, DK-2800 Kgs. Lyngby. \\ ${ }^{\mathrm{d}}$ Technical University of Denmark, Department of Chemistry, Kemitorvet, DK-2800 Kgs. \\ Lyngby.
}

\begin{abstract}
${ }^{119} \mathrm{Sn}$ CPMG MAS NMR was applied to study the adsorption of acetonitrile, methanol, isopropanol, isobutanol and water over $\mathrm{Sn}-\mathrm{BEA}$ enriched with ${ }^{119} \mathrm{Sn}$ isotope. Two signals observed at ca. -422 and -443 ppm over dehydrated samples were attributed to tetracoordinated framework tin sites with strong and weak Lewis acidity, respectively. The adsorption of
\end{abstract}


acetonitrile and methanol resulted in observation of pentacoordinated tin species, due to the formation of 1:1 adsorption complexes over both Sn-sites. Water adsorption led first to formation of pentacoordinated tin species, which were further converted into hexacoordinated species at longer reaction times. The latter transformation was found to be kinetically limited and was attributed to chemical interaction of tin sites with water, such as hydrolysis of Si-O-Sn bonds. The adsorption of isopropanol and isobutanol was accompanied by the formation of pentacoordinated Sn species in the case of weak sites and hexacoordinated Sn over sites with strong Lewis acidity, pointing to the possibility of dissociative adsorption of secondary alcohols over strong Sn-sites.

\section{INTRODUCTION}

Sn-BEA zeotypes are promising heterogeneous catalysts for the conversion of sugars into methyl lactate ${ }^{1,2}$, the isomerization of glucose into fructose $e^{2-5}$ and other important reactions such as Baeyer-Villiger oxidations ${ }^{6,7}$, Meerwein-Ponndorf-Verley-Oppenauer redox reactions ${ }^{8}$, ringopening hydration of epoxides ${ }^{9}$ etc. The exceptional catalytic properties of Sn-BEA are due to the combination of their Lewis acidity, the hydrophobic microenvironment around active sites and the ability to catalyze reactions in aqueous media. These properties make Sn-BEA especially relevant for biomass processing ${ }^{3,10,11}$.

It is generally accepted that tin atoms, which isomorphously substitute silicon in the zeolite framework, are the catalytically active sites in Sn-BEA ${ }^{10-12}$. However, the exact configuration of these sites has not yet been unambiguously determined although numerous techniques including quantum-chemical calculations ${ }^{13-16}$, DR-UV-Vis ${ }^{10}$, FTIR $^{12,17-20}$, Mössbauer $^{21}$ and NMR spectroscopy ${ }^{21-24}$ have been applied for this purpose. 
Among the different approaches, the application of probe molecules was shown to be the most fruitful for characterization of tin sites and their local environment ${ }^{8,11,12,14,17-20,23,25-30}$. Besides that, probe molecules were particularly useful in deducing the catalytic behavior by providing insights into the interaction of the active site with solvents, reactants, intermediates and products in reactions catalyzed by Sn-BEA. Different types of probe molecules including pyridine $(\mathrm{Py})^{8,18,25}$, alkyl substituted pyridines ${ }^{8}$, ammonia ${ }^{14,18,26}$, deuterated acetonitrile $\left(\mathrm{CD}_{3} \mathrm{CN}\right)^{12,14,18-}$ 20,28, cyclohexanone ${ }^{8,30}$, alkyl substituted cyclohexanone ${ }^{8}$, dimethyl ether ${ }^{20}$, n-propylamine ${ }^{18}$, alcohols ${ }^{14,20,27}$, glucose and water $^{14,17,19,20,23,27}$ were applied to characterize tin sites.

It should be noted that most studies involving probe molecules has been monitored by FTIR and TPD techniques ${ }^{8,12,17-20,26,28-30}$. Both these techniques provide comprehensive information on the state of the adsorbed probe molecule, indirectly providing information on the nature of the Sn-sites. The direct detection of Sn-sites interacting with probe molecules, however, is highly desirable to confirm the conclusions made from indirect methods as well as to get deeper insight into the structure and environment of Sn-sites interacting with different probe molecules.

This direct information can be best obtained by ${ }^{119} \mathrm{Sn}$ MAS NMR, a reliable method for probing ${ }^{119} \mathrm{Sn}$ nuclei and their environment ${ }^{5,21-24,31-33}$. In particular, ${ }^{119} \mathrm{Sn}$ MAS NMR allows for distinguishing between framework and extraframework tin nuclei formed during the synthesis, and provides information on tin coordination and T-site distribution in the material. Thus, extraframework $\mathrm{SnO}_{2}$ species were shown to exhibit a signal at ca. $-604 \mathrm{ppm}$, whereas tetrahedral Sn-sites were characterized by a number of signals in the range of -420 to $-450 \mathrm{ppm}$ when dehydrated and in the range of -650 to $-730 \mathrm{ppm}$ when hydrated ${ }^{24,26,31}$. However, recording of ${ }^{119} \mathrm{Sn}$ MAS NMR spectra of tin-containing zeolites with sufficient resolution is timeconsuming, even in samples enriched with the ${ }^{119} \mathrm{Sn}$ isotope, due to low tin content in Sn-BEA 
(about 1-2 wt.\%). Sophisticated NMR techniques help to overcome this problem. The use of DNP-NMR is a good example $e^{21,22}$. In this case, the sensitivity is enhanced by $28-75$ times by exploiting the transfer of electron spin to the investigated nucleus. However, the specific biradical molecules used as polarizing sources and solvents in combination with low-temperature requirements $(\mathrm{T}=100 \mathrm{~K})$ do not allow the use of probe molecules for sample characterization.

In the present work, we focus on applying a different strategy to optimize the use of ${ }^{119} \mathrm{Sn}$ MAS NMR spectroscopy to study the interaction of Sn-sites with relevant probe molecules and solvents. Specifically, the adaptation of the Carr-Purcell-Meiboom-Gill (CPMG) echo train acquisition ${ }^{24}$ used to enhance the signal-to-noise ratio combined with the application of ${ }^{119} \mathrm{Sn}$ enrichment allows a detailed study of the interaction between Sn-sites and the probe molecules within a reasonable timeframe. To assess the nature of different $\mathrm{Sn}$ sites and their reactivity, acetonitrile, methanol, isopropanol, isobutanol and water are used as probe molecules.

\section{EXPERIMENTAL METHODS}

\section{$\underline{\text { Synthesis of }}{ }^{119} \mathrm{Sn}-\mathrm{BEA}$}

Labelled and unlabeled Sn-BEA materials were synthesized using non-seeding procedure developed by Tolborg et $a .^{34}$. In the case of unlabeled Sn-BEA, $\mathrm{SnCl}_{4} * 5 \mathrm{H}_{2} \mathrm{O}$ was used as a tin source. For the preparation of the labeled tin source, metallic tin enriched with ${ }^{119}$ Sn isotope was dissolved in $\mathrm{HCl}$ as proposed by Renz et al. ${ }^{7}$. To avoid any undesirable oxidation states of tin, in this work an excess of $\mathrm{H}_{2} \mathrm{O}_{2}$ was added after dissolution of tin in $\mathrm{HCl}$. The resulting tin source thereby comprised an aqueous solution of $\mathrm{H}_{2}{ }^{119} \mathrm{SnCl}_{6}$. The molar composition of the gel after the addition of $\mathrm{H}_{2}{ }^{119} \mathrm{SnCl}_{6}$ was as described in 35 . The details of preparation are given in Supporting Information. 


\section{$\underline{\text { Pretreatment conditions }}$}

As-synthesized samples were calcined under static conditions in air. A small amount of the sample powder was placed in a porcelain crucible in a muffle furnace. The calcination procedure involved: 1) heating to $550{ }^{\circ} \mathrm{C}, 4{ }^{\circ} \mathrm{C} / \mathrm{min}$; and 2) maintaining at $550{ }^{\circ} \mathrm{C}$ for $15 \mathrm{~h}$.

The typical dehydration procedure before adsorption experiments involved treatment of the calcined sample at $250{ }^{\circ} \mathrm{C}$ under vacuum conditions for $3 \mathrm{~h}$. In some experiments, the dehydration temperature was varied within $100-400^{\circ} \mathrm{C}$. To study the interaction of probe molecules with Sn-sites the molecules were adsorbed on the dehydrated sample at ambient temperature under vacuum conditions.

Acetonitrile, methanol, isopropanol, isobutanol and water were used as probe molecules. Acetonitrile and alcohols were dosed volumetrically in the range of $0.5-4$ molecules per Sn atom. After the adsorption, the sample was transferred into the NMR rotor in a glovebox and sealed; then NMR spectrum was measured. The kinetics of the interaction of water with Sn-sites was studied directly in the NMR spectrometer after the adsorption of 4 molecules of water per Sn site at ambient temperature. The duration of the experiment was 67 hours. NMR spectra were acquired at $7 \mathrm{~h}$ intervals. After that, the sample was removed from the NMR spectrometer and kept in a closed rotor for 1 month whereafter a final NMR spectrum was measured.

\section{$\underline{\text { Characterization }}$}

X-ray diffraction analysis was performed on a D2 PHASER (Bruker) diffractometer, Tube power: $30 \mathrm{kV}(10 \mathrm{~mA})$. XRD patterns were measured in the range of $2 \theta=5-50^{\circ}$ using filtered $\mathrm{CuK} \alpha(\lambda=0.154060 \mathrm{~nm})$ radiation. SEM images were obtained with an electron microscope Hitachi TM-3030. The studies were carried out with an accelerating voltage of $15 \mathrm{kV}$; all samples were coated by Au before analysis. 
${ }^{119}$ Sn MAS NMR spectra were recorded on AVANCE-II 400WB (Bruker) spectrometer (9.4 T). Triple-resonance $4 \mathrm{~mm}$ MAS DVT probe (BRUKER) was used for detection, MAS frequency being $12 \mathrm{kHz}$. Direct polarization combined with CPMG echo-train acquisition (DPCPMG) was used as a main pulse sequence ${ }^{24}$. Spectra of dehydrated samples were measured applying 600 echoes without any proton decoupling. For the hydrated samples and samples with adsorbed probe molecules, high-power ${ }^{1} \mathrm{H}$ decoupling was used (SW-TPPM, $\tau=8 \mu \mathrm{s}, \varphi=15^{\circ}$, $\left.\omega\left(\mathrm{B}_{1}\right)=105 \mathrm{kHz}\right)$ with only 25 echo in CPMG echo-train. For some samples, cross-polarization combined with CPMG echo-train acquisition (CP-CPMG) was applied. The ${ }^{119} \mathrm{Sn}$ NMR chemical shifts were calibrated by $\mathrm{SnO}_{2}$ as secondary external reference $(-604.3 \mathrm{ppm})^{36}$. For spectra processing, the TopSpin 2.1 (Bruker) program was used. Parameters of line shape were calculated using DMFIT software ${ }^{37}$. The main parameters of NMR experiments are given in Table S1 (Supporting Information).

\section{RESULTS AND DISCUSSION}

\section{$\underline{\text { Preparation and characterization of }{ }^{119} \mathrm{Sn}-\mathrm{BEA}}$}

Structural and morphological characteristics of Sn-BEA synthesized with labeled ( $\left.{ }^{119} \mathrm{Sn}-\mathrm{BEA}\right)$ and unlabeled (Sn-BEA) tin sources are compared in Figs. S1 and S2 (Supporting Information). The results show that the different tin source did not affect the main characteristics of the samples. Overall, the labeled and unlabeled materials show the same structure, crystallinity, crystal size and morphology typical for Sn-BEA materials with $\mathrm{Si} / \mathrm{Sn}=200 \mathrm{ratio}^{7,34}$.

The ${ }^{119}$ Sn MAS NMR spectra of calcined hydrated and dehydrated samples are illustrated in Fig. 1. Similar spectra are observed for ${ }^{119} \mathrm{Sn}-\mathrm{BEA}$ and Sn-BEA samples, again pointing to an identical tin environment in labeled and unlabeled materials. In the spectra of the hydrated 
samples two signals at ca. -689 and -703 ppm are observed. These signals were reported by other groups $5,7,21,23,26,31$ and were attributed in the literature to hexacoordinated tin atoms, corresponding to "closed" Sn-sites with two water molecules in the first coordination sphere (I), "open" Sn-sites with two water molecules in the first coordination sphere (II) or "hydrolyzedopen" Sn-sites with one water molecule in the first coordination sphere (III) $)^{5,21,31}$ :

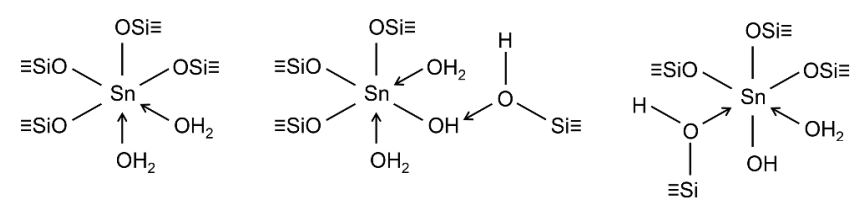

(I)

(II)

(III)

However, no unambiguous assignment of the resonances at ca. -689 and -703 ppm has been made so far.

It should be noted that no extra framework $\mathrm{Sn}$ or $\mathrm{Sn}$ connected with fluoride ions are present in the studied material as confirmed by the absence of a narrow peak at ca. $-604 \mathrm{ppm}^{7,26,38}$ and -730 $\mathrm{ppm}^{23}$ in the Sn-NMR spectrum, respectively.

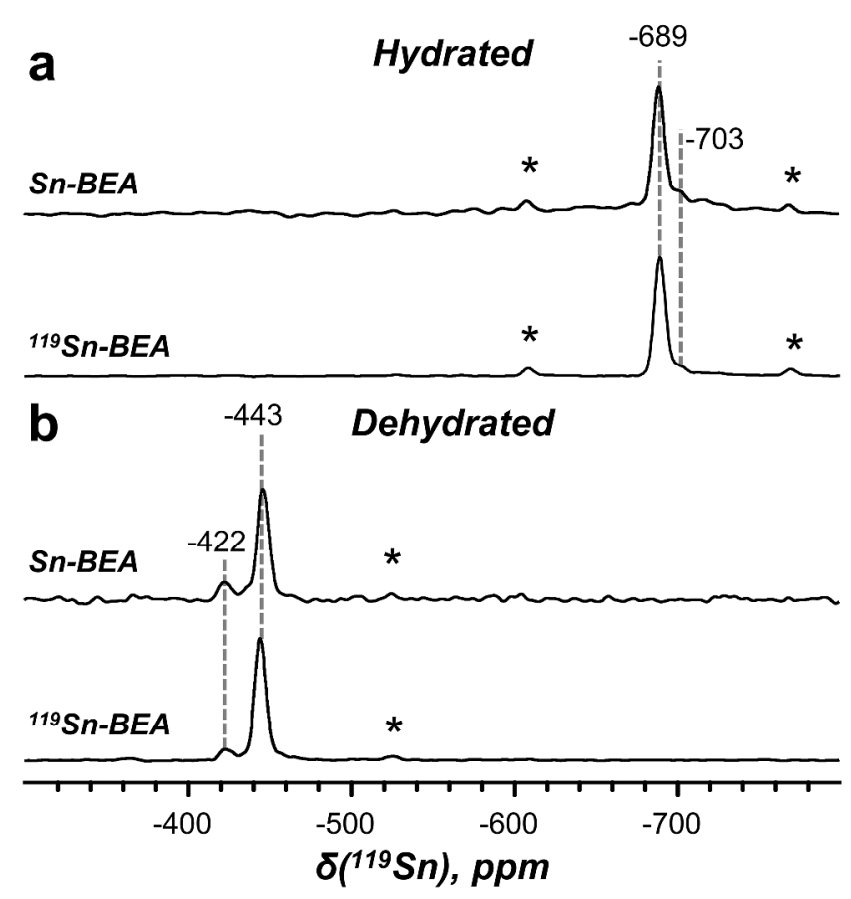


Figure 1. ${ }^{119}$ Sn CP-CPMG MAS NMR spectra of hydrated (a) and ${ }^{119}$ Sn DP-CPMG MAS NMR spectra of dehydrated (b) Sn-BEA and ${ }^{119}$ Sn-BEA samples. Sidebands are marked with asterisks.

Upon dehydration of the samples, the signals corresponding to hexacoordinated tin disappear and two signals at -422 and -443 ppm appear in agreement with the literature data ${ }^{5,7,23,26}$. Bermejo-Deval et $a .^{5}$ have shown that the signal at ca. $-420 \mathrm{ppm}$ is amenable to crosspolarization. Based on the argumentation that this is the only site with a proton source in its proximity they assigned this signal to the so-called "open" site (IV); and as a consequence the signal at -443 ppm was assigned to "closed" sites (V):

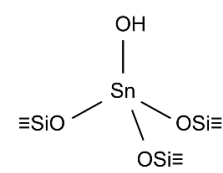

(IV)

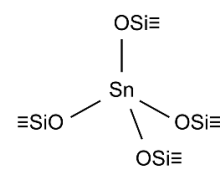

(V)

In this work, we tried to confirm this assignment by applying cross-polarization conditions to our samples. However, we were not able to get any signal after sample dehydration at $250^{\circ} \mathrm{C}$ under vacuum (Fig. S3, Supporting Information). Comparing the pre-treatment conditions in our experiments with those applied in the work of Bermejo-Deval et al. ${ }^{5}$, it can be noticed that the authors used a dehydration pre-treatment at $120{ }^{\circ} \mathrm{C}$, whereas $250{ }^{\circ} \mathrm{C}$ were used in our experiments. The decrease of the pre-treatment temperature of our sample to $150{ }^{\circ} \mathrm{C}$ revealed the appearance of signals at ca. -418 and -403 ppm (Fig. S3, Supporting Information). The intensity of these signals increased further when the temperature was decreased to $100{ }^{\circ} \mathrm{C}$. This result confirms the presence of small amount of defect sites, however they are shown to condense and thereby disappear at higher dehydration temperatures. Since the signal at -422 ppm was not amenable to cross-polarization in our experiments we cannot attribute it to "open" sites based on our data. 
At present, no direct correlation has been established between the different signals in the spectra of hydrated and dehydrated samples. The quantification of the NMR signals of hydrated ${ }^{119} \mathrm{Sn}$-BEA sample obtained in this study points that the ratio between integral intensities of the signals at ca. -689 and -703 ppm corresponds to $87 / 13$. For a dehydrated sample of ${ }^{119}$ Sn-BEA the ratio between the integrated signals at ca. -422 and $-443 \mathrm{ppm}$ is $15 / 85$. This suggests that the signal obtained at ca. -703 ppm upon dehydration leads to the signal found at $-422 \mathrm{ppm}$ with a similar correlation existing for the signals at -689 and $-443 \mathrm{ppm}$. Further studies are required, however, to confirm this hypothesis.

\section{Adsorption of acetonitrile}

The adsorption of acetonitrile is commonly used for the analysis of different Sn-sites and their Lewis acid strength ${ }^{12,17-20,33}$. In most cases, the adsorption of deuterated acetonitrile is monitored by FTIR spectroscopy. Additionally, some reports on the application of temperature programmed desorption (TPD) techniques are also available ${ }^{17,20}$. Application of this probe molecule allows for the differentiation between framework and extraframework tin sites ${ }^{12,20}$. Furthermore, based on the FTIR spectroscopy of deuterated acetonitrile displaying two bands at ca. 2316 and $2308 \mathrm{~cm}^{-1}$, Boronat et al. ${ }^{12}$ suggested the existence of two different framework sites in Sn-BEA, namely "open" and "closed" sites as mentioned earlier. The first band was assigned to the "open" Sn-site (IV) with three oxygen bonds connected to the zeolite framework and one to an $-\mathrm{OH}$ group. The second band was attributed to a closed site (V) with four oxygen bonds connected to the zeolite framework. In the same study it was shown that acetonitrile interacts more strongly with the site giving $2316 \mathrm{~cm}^{-1}$ vibration and that there is a correlation between the acetonitrile adsorption band at $2316 \mathrm{~cm}^{-1}$ and the catalytic activity in the Bayer-Villiger oxidation of adamantanone. The assignment of the two bands was however not supported by other (more recent) reports ${ }^{17,20}$. Roy 
et al. observed a single band at ca. $2310 \mathrm{~cm}^{-1}$, suggesting that the observation of the additional line at $2316 \mathrm{~cm}^{-1}$ was associated with solvent effects due to the presence or absence of additional acetonitrile molecules in the vicinity ${ }^{20}$. Therefore, the information on the state of Sn atoms during the adsorption of acetonitrile is highly desirable.

In this study, we aimed to clarify the state of various $\mathrm{Sn}$ atoms during acetonitrile adsorption by ${ }^{119} \mathrm{Sn}$ MAS NMR techniques. Different amounts of acetonitrile in the range of $0.5-4$ molecules per tin atom were loaded onto the ${ }^{119} \mathrm{Sn}$-BEA sample and the changes in the state of tin were monitored by ${ }^{119} \mathrm{Sn}$ DP-CPMG/MAS NMR. The results are shown in Fig. 2.

Upon adsorption of the first aliquot of acetonitrile $\left(\mathrm{CH}_{3} \mathrm{CN} / \mathrm{Sn}=0.5\right)$ both signals at -422 and 443 ppm disappear. Instead, two new signals appear at -480 and $-587 \mathrm{ppm}$ with similar ratio of integrated peak intensity as for the initial peaks at -422 and $-443 \mathrm{ppm}$. This leads us to assume that the weak signal at ca. $-422 \mathrm{ppm}$ shifts to $-587 \mathrm{ppm}$, whereas the intensive resonance at -443 ppm yields a broad signal centered at $-480 \mathrm{ppm}$. Upon further dosing of acetonitrile, the two sites behave differently. The position of the weak signal at ca. -590 ppm practically does not change with higher loadings (Fig. 2b). Conversely, the signal with the larger integral intensity continues to move to higher field and reaches a chemical shift of $-570 \mathrm{ppm}$ at acetonitrile loadings of four molecules per tin site. At the same time the line shape of the signal changes, becoming sharper and well-defined. Further increase of loadings does not affect the peak position and shape. 
a
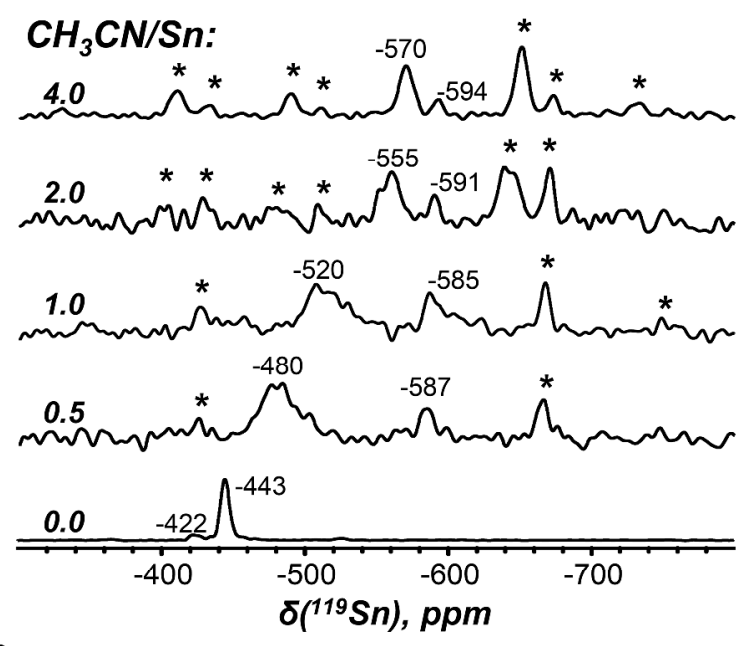

b

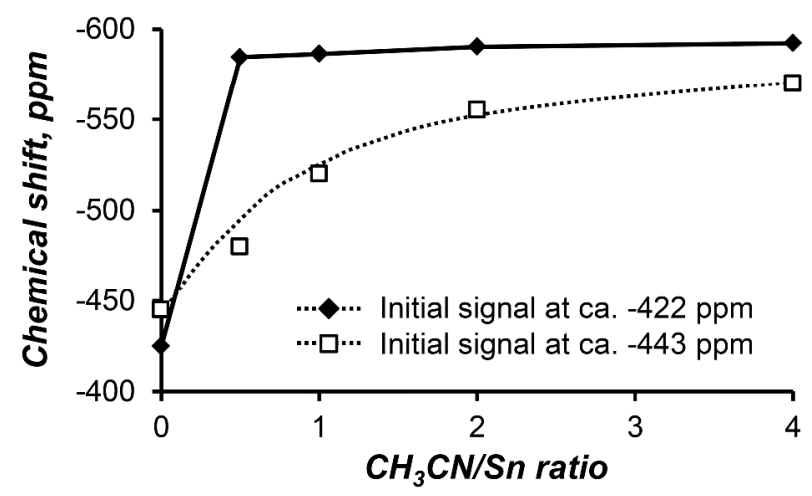

Figure 2. ${ }^{119}$ Sn DP-CPMG/MAS NMR spectra of dehydrated ${ }^{119}$ Sn-BEA zeolite before and after loading of acetonitrile in different amounts (a) and variation of chemical shift of signals at ca. 422 and -443 ppm with acetonitrile loading (b). Sidebands are marked with asterisks.

The variation of the chemical shift and the line shape with increased loadings could be due to fast exchange between different adsorption sites or between adsorbed and gaseous phases. This phenomenon has been described in detail by Bain ${ }^{39}$. At low loadings, the population of sites is rather low and only strong Sn-sites are permanently occupied. The rest of the adsorbate can exchange between the adsorbed and gaseous phases or between the different weak sites related to and not related to tin (for instance, weak Sn Lewis sites and silanol groups). As a result, of this exchange a weighted average of the chemical shift between occupied and pristine Sn-sites is 
observed. At high loadings, all sites become occupied and the chemical shift observed after saturation corresponds to Sn-sites with adsorbed acetonitrile (Fig. 2b).

The position and parameters of the shape of NMR signals at ca. -570 and -594 ppm are similar to those calculated for pentacoordinated closed Sn-sites by Wolf et al. ${ }^{21,31}$. Although their calculations were performed for the adsorption of water molecules, the chemical shift should not change drastically in the case of acetonitrile adsorption. No lines around ca. -703 ppm are observed in the NMR spectra even at high loadings, suggesting that no hexacoordinated $\mathrm{Sn}$ is formed upon the adsorption of acetonitrile. Thus, only one molecule of acetonitrile binds to the Sn-sites despite the high dosage of up to 4 molecules of acetonitrile per Sn site. These findings confirm the conclusion on equimolar stoichiometry of acetonitrile adsorption made by Harris et $a l{ }^{18}$ using FTIR spectroscopy of adsorbed deuterated acetonitrile. Furthermore, our results suggest that the Sn-site that gives a signal at $-422 \mathrm{ppm}$ binds acetonitrile stronger than the site at $-443 \mathrm{ppm}$, which is in excellent agreement with previous observations made by the groups of Corma $^{12}$ and Davis ${ }^{5}$. In this contribution, we, however, cannot comment on the assignment of these signals to "open" and "closed" sites, respectively.

\section{$\underline{\text { Adsorption of alcohols }}$}

Alcohols, especially methanol, are used as solvents and often substrates in reactions catalyzed by $\mathrm{Sn-BEA}{ }^{1,30,40}$, making it essential to study adsorption of alcohols over Sn-BEA in order to understand the state of tin directly during the catalytic reaction mixture. Roy et al. ${ }^{20}$ studied the adsorption of 2-methyl-2-propanol and diethyl ether with Sn-BEA using TPD-TGA techniques. It was shown that 2-methyl-2-propanol and diethyl ether interact differently with Sn-BEA. Diethyl ether yields a 1:1 adsorption complex with tin and desorbs intact. On the contrary, 2methyl-2-propanol gives coverages of more than twice the tin content in the analyzed sample. 
Besides that, part of 2-methyl-2-propanol molecules desorbs as butene and water. This work impelled us to monitor the adsorption of alcohol molecules with smaller (methanol) and larger sizes (isopropanol, isobutanol).

Fig. 3a shows the comparison of ${ }^{119} \mathrm{Sn}$ DP-CPMG/MAS NMR spectra recorded after adsorption of alcohol molecules over dehydrated ${ }^{119}$ Sn-BEA together with the spectrum obtained for acetonitrile. In all the experiments, the adsorbate loadings were close to 4 molecules per Sn atom. The results show that the adsorption of methanol gives a spectrum very similar to that of acetonitrile: two lines corresponding to pentacoordinated Sn-sites are observed at -576 and -588 ppm.

In the case of isopropanol and isobutanol, a slightly different picture is observed (Fig. 3a). In particular, only intensive NMR line is detected in the range of -582 to $-586 \mathrm{ppm}$, while the weak resonance at ca. $-590 \mathrm{ppm}$ corresponding to the adsorption on sites with strong acidity is not seen. To further assess this behavior, the adsorption of small aliquots of isobutanol was monitored. The adsorption of small amounts of isobutanol reveals the presence of this signal (Fig. 3b) at ca. -589 ppm, however the increase of isobutanol loadings leads to its vanishing. The decrease of the signal at ca. $-589 \mathrm{ppm}$ is accompanied by the appearance of a small resonance at ca. $-703 \mathrm{ppm}$, which is more pronounced with cross-polarization. The latter signal can be attributed to hexacoordinated tin atoms. The reasons for the observation of hexacoordinated tin as a result of interaction of secondary alcohols with strong tin sites will be discussed later. 

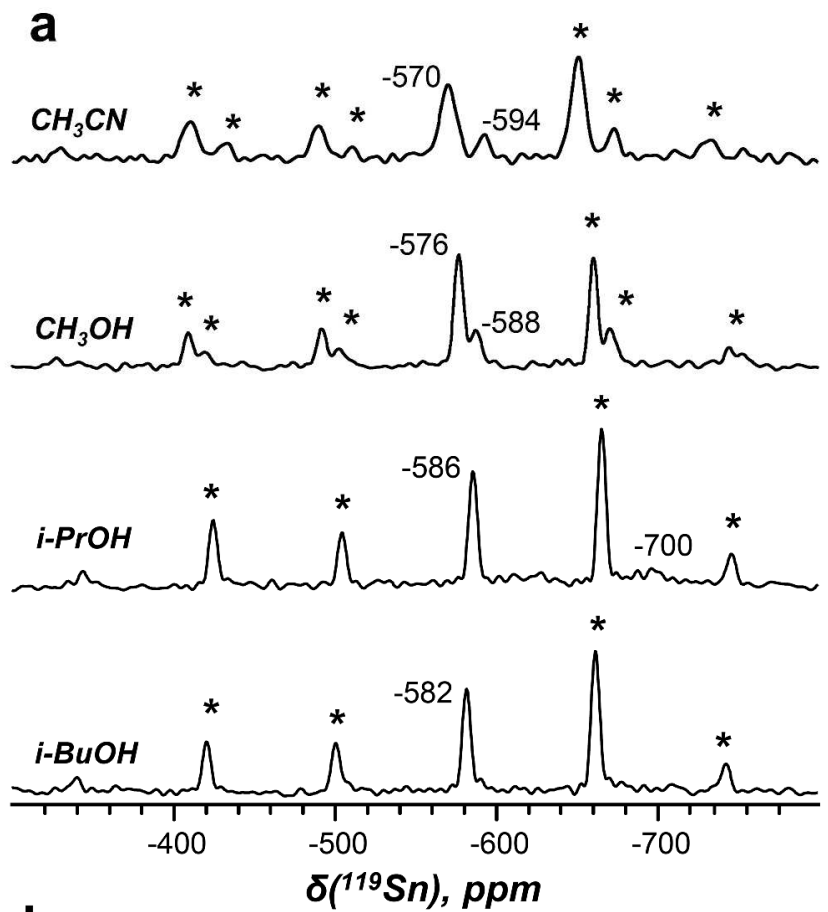

b
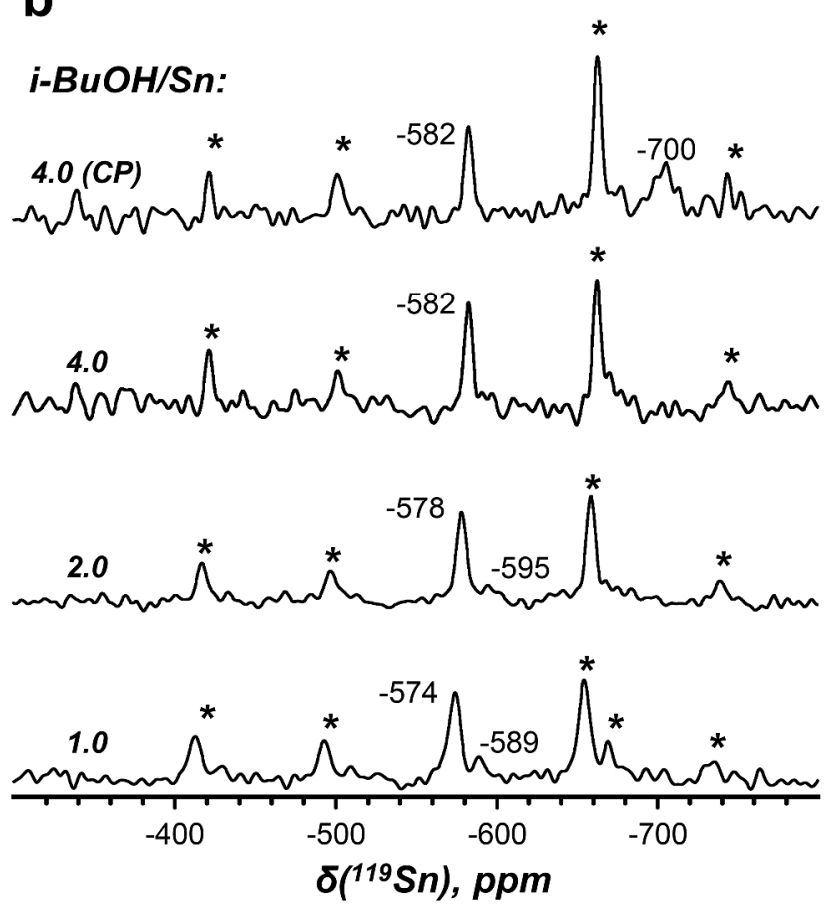

Figure 3. ${ }^{119} \mathrm{Sn}$ DP-CPMG MAS NMR spectra of acetonitrile, methanol, isopropanol and isobutanol adsorbed over ${ }^{119} \mathrm{Sn}-\mathrm{BEA}$ in the ratio of adsorbate/Sn $=4(\mathrm{a})$; variation of ${ }^{119} \mathrm{Sn} \mathrm{DP}$ CPMG MAS NMR spectra with isobutanol loadings (b). Spectrum 4.0 (CP) is recorded using ${ }^{119}$ Sn CP-CPMG MAS NMR. Sidebands are marked by asterisks. 


\section{Adsorption of water}

The interaction with water is of special interest, since aqueous phase reactions are an integral part of biomass processing. Furthermore, even when alcohol is used as solvent, water is often present in the reaction mixture either as an impurity or as a by-product ${ }^{30,40}$. Finally, tin sites in the catalyst are usually in a hydrated state as the catalyst is seldom dried prior to use. Changes in catalysts structure as a result of hydration could be responsible for a number of observations responsible for catalytic activity. Therefore, one cannot consider tin sites in Sn-BEA catalysts inseparably from water in most reactions.

The adsorption of water on Sn-BEA has been studied in several reports ${ }^{17,19,20,23,27,31}$. The comparison of the isotherms of water adsorption over various hydrophobic zeolites obtained in fluoride media showed that the amount of water adsorbed over Sn-BEA was higher than on TiBEA and Si-BEA by a factor of $2^{27}$. Theoretic calculations suggested stronger adsorption of water on Sn-BEA as compared to other substrates, such as $\mathrm{NH}_{3}$, alcohols and acetonitrile ${ }^{13-16}$. This was also confirmed experimentally ${ }^{17,19,20,23}$. Furthermore, Courtney et al. ${ }^{17}$ revealed that the adsorption of water is accompanied by the formation of $\mathrm{SiOH}$ groups. The process was found to be very slow (requiring several days), nevertheless shown to occur even at mild relative humidity and ambient temperature. At $98^{\circ} \mathrm{C}$ in liquid water $\mathrm{SiOH}$ formation was found to happen in less than $1 \mathrm{~h}$. These silanol groups were stable at temperatures as high as $400{ }^{\circ} \mathrm{C}$ and found to condense in the range of $400-700{ }^{\circ} \mathrm{C}$. Based on these results the authors concluded that dissociative adsorption of water occurs over Sn-BEA. Additionally, it was found out that the extent of hydroxylation is proportional to the Sn content. This conclusion was further supported by the results of Otomo et al. ${ }^{19}$ by studying the ion exchange of Sn-BEA with different alkali 
cations. They found out that not only "open" but also "closed" sites without adjacent silanol groups could be ion-exchanged through the hydrolysis of $\mathrm{Si}-\mathrm{O}-\mathrm{Sn}$ bonds. In the case of $\mathrm{Cs}^{+}, \mathrm{K}^{+}$ and $\mathrm{NH}_{4}^{+}$cations, the ratio of cation/Sn reached 1, indicating that all Sn-sites were fully converted into "open" sites and exchanged. This is a relevant finding, as the exchange with alkali metal salts has been shown to affect the catalytic activity and selectivity in several reactions; either facilitating epimerization (instead of isomerization) of sugars or changing the reaction pathway from a retro-aldol mechanism (yielding methyl lactate and similar products) to a $\beta$ dehydration mechanism facilitating the formation of newly discovered bio-monomers ${ }^{33,41,42}$.

The state of Sn during hydration was studied by ${ }^{119} \mathrm{Sn}$ MAS NMR by Hwang et al. ${ }^{23}$. The authors observed mainly hexacoordinated tin after adsorption of two molecules of water per tin atom. Very small signals attributed to pentacoordinated tin were also detected.

To get deeper insight into the interaction of water molecules with the Sn-sites present in SnBEA, we studied the kinetics of water adsorption. The dehydrated sample was exposed to a $\mathrm{H}_{2} \mathrm{O}$ aliquot corresponding to $\mathrm{H}_{2} \mathrm{O} / \mathrm{Sn}=4.0$ and the development in NMR signals was monitored with time. Fig. 4 shows the NMR spectra obtained before and after the exposure to water. After three hours of exposure three signals have appeared: an intensive signal at ca. $-581 \mathrm{ppm}$ (pentacoordinated Sn-sites) and two weak signals at ca. -689 and -703 ppm (hexacoordinated Snsites). In agreement with earlier observations, the small signal at ca. $-703 \mathrm{ppm}$ arises from the signal at ca. $-422 \mathrm{ppm}$ in the dehydrated sample, whereas the signals at -580 and $-689 \mathrm{ppm}$ originate from the signal at ca. $-443 \mathrm{ppm}$. The analysis of the intensities of the lines suggests that the Sn sites with strong acidic character observed at $-422 \mathrm{ppm}$ in the dehydrated sample give predominantly hexacoordinated sites already at the initial steps of the hydration. The small signal observed in the range of -590 to $-600 \mathrm{ppm}$, could be attributed to pentacoordinated tin, but it is 
on the level of the noise. On the contrary, Sn-sites associated with weak acidity (signal at ca. $443 \mathrm{ppm}$ in the dehydrated sample) are converted mostly to pentacoordinated tin, giving the signal at ca. $-581 \mathrm{ppm}$.

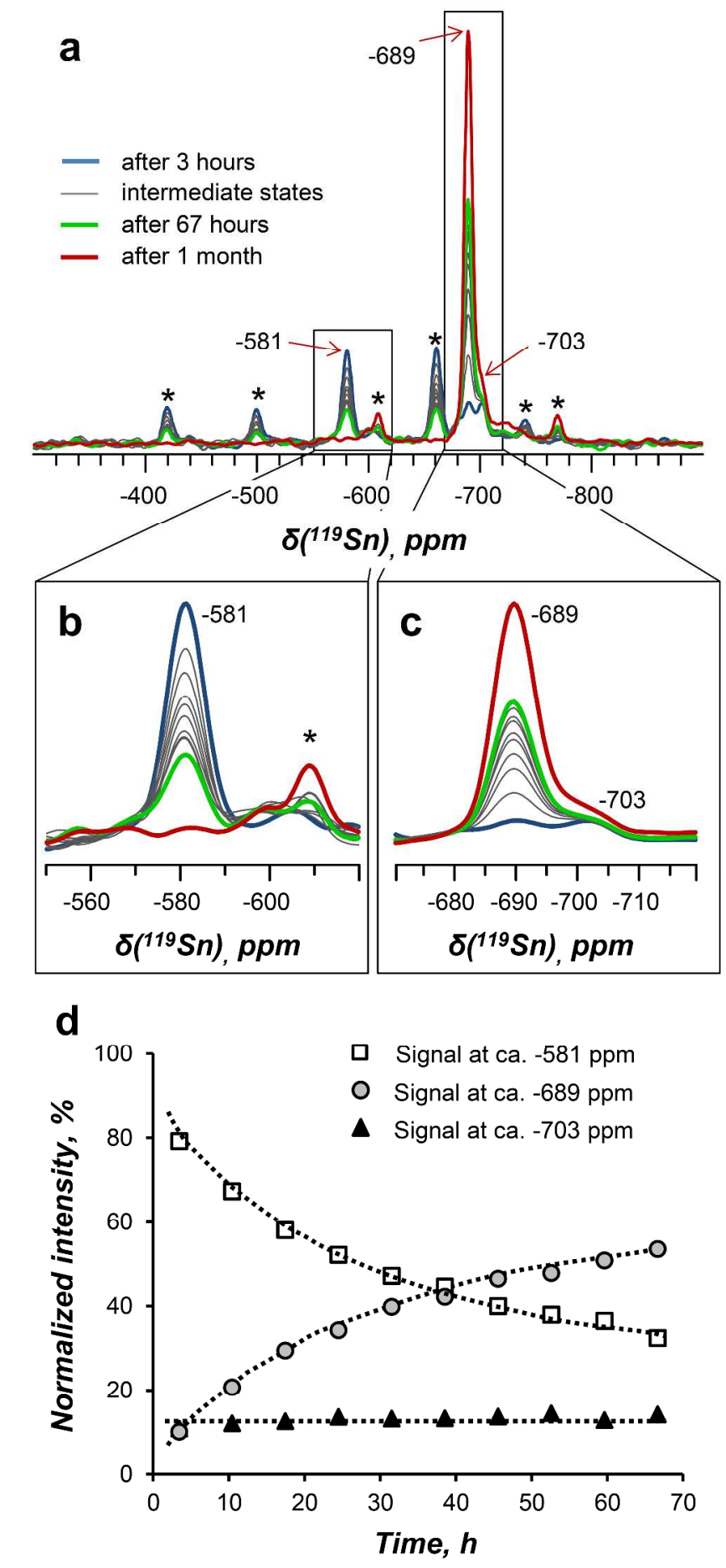


Figure 4. Variation of ${ }^{119} \mathrm{Sn}$ DP-CPMG MAS NMR spectra of ${ }^{119}$ Sn-BEA with time (a) after exposure to water $\left(\mathrm{H}_{2} \mathrm{O} / \mathrm{Sn}=4\right)$. The regions from -550 to $-625 \mathrm{ppm}(\mathrm{b})$ and $-675--710 \mathrm{ppm}$ (c) are highlighted. Variation of normalized integrated intensity of ${ }^{119}$ Sn MAS NMR signals at ca. 581, -689 and -703 ppm with time of exposure to water (d). Sidebands are marked as asterisks.

The changes in signals intensities during $67 \mathrm{~h}$ of experiment are shown in Fig. 4d. The results show that the intensity of the signal at ca. $-581 \mathrm{ppm}$ decreases down to $32 \%$, whereas the intensity of the signal at ca. -690 ppm increases up to $54 \%$. The signal at ca. -703 ppm remains at the level of $11-14 \%$ during the whole duration of experiment (Fig. $4 d$ ).

After 1 month, the signal at ca. -581 ppm disappears completely, whereas the two signals at ca. -689 and -703 ppm remain (Fig. 4) and the spectrum becomes very similar to those of fully hydrated samples (for comparison see Figs. 1 and 4, red spectrum). The ratio between the intensities of signals at ca. -689 and -703 ppm is $86 / 14$, which is very close to hydrated sample $(87 / 13)$.

The analysis of CP-CPMG MAS NMR spectra obtained over ${ }^{119}$ Sn-BEA sample after adsorption of water (Fig. S4) points that pentacoordinated Sn sites $(-581 \mathrm{ppm})$ does not show any signal when cross-polarization is applied. On the contrary, the signals at ca. -689 and -703 ppm attributed to hexacoordinated tin are amenable to cross-polarization. The latter observation can be accounted for by the formation of hydrolyzed open Sn sites (III).

It is important to note that dehydration of the sample after adsorption of water results in complete restoration of the spectrum of dehydrated sample (Fig. S5). These observations suggest that the changes observed during hydration/dehydration are fully reversible.

To summarize, Sn-sites with strong Lewis acidic character (-422 ppm) and weak Lewis acidic character (-443 ppm) show different behavior upon interaction with water. The strong sites react 
faster than the time-scale of our experiment, resulting in the immediate transformation of tetracoordinated tin into the hexacoordinated state. On the contrary, weak sites are first transformed into the pentacoordinated state followed by very slow (up to one month at ambient temperature) rearrangement into hexacoordinated state. These observations are in line with previous findings ${ }^{17,19}$ and point to dissociative adsorption of water leading to hydrolysis of Si-OSn bounds. Furthermore, our results suggest that in fully hydrated samples all Sn-sites are hydrolyzed.

\section{IMPLICATIONS}

${ }^{119}$ Sn CPMG MAS NMR of adsorbed probe molecules revealed the existence of two different framework Sn-sites with different adsorption properties:

- Sn-sites associated with strong Lewis acidity and characterized by an NMR signal at ca. $422 \mathrm{ppm}$

- $\quad$ Sn-sites with lower acidity and an NMR signal located at -443 ppm.

Our data do not allow for these sites to be attributed as "open" or "closed" as it was proposed in other reports ${ }^{5,12}$, since none of the signals observed is amenable to cross-polarization. We suppose that the origin of different signals is more likely due to the different locations in the framework of Sn-BEA, as it has also been suggested by theoretical calculations ${ }^{31}$. According to our data, the ratio between these sites can be changed by adjusting of synthesis conditions, variation of tin content ${ }^{35}$ and pretreatment conditions ${ }^{24}$.

Table 1. Parameters of NMR line shape $\left(\delta_{\text {iso }}, \Omega\right.$ and $\left.\kappa\right)$ of signals corresponding to pentacoordinated tin sites in Sn-BEA bonded to different probe molecules.

\begin{tabular}{lrlrl}
\hline $\begin{array}{l}\text { Expected } \\
\text { of }\end{array}$ & $\begin{array}{r}\text { structure } \\
\text { adsorption }\end{array}$ & Type of & NMR parameter & Reference \\
\hline
\end{tabular}




\begin{tabular}{|c|c|c|c|c|c|}
\hline complex & Sn-site & $\delta_{\text {iso }}^{\text {a }}$, ppm & $\begin{array}{ll}\Omega & \text { (span), } \\
\text { ppm }\end{array}$ & к (skew) & \\
\hline \multirow{3}{*}{$\left(\mathrm{H}_{2} \mathrm{O}\right) \mathrm{Sn}^{\mathrm{V}}(\mathrm{OSi} \equiv)_{4}$} & - & -575 & 393 & -0.47 & $21^{\mathrm{b}}$ \\
\hline & - & $-560 \ldots-585^{c}$ & $360 \ldots 420^{\mathrm{c}}$ & n.d. & $31^{\mathrm{b}}$ \\
\hline & Weak & -581 & $360 \pm 20$ & $-0.8 \pm 0.2$ & \multirow{7}{*}{ this work $^{\mathrm{d}}$} \\
\hline \multirow{2}{*}{$\left(\mathrm{CH}_{3} \mathrm{CN}\right) \mathrm{Sn}^{\mathrm{V}}(\mathrm{OSi} \equiv)_{4}$} & Strong & -594 & $415 \pm 30$ & $-0.8 \pm 0.2$ & \\
\hline & Weak & -570 & $390 \pm 20$ & $-0.7 \pm 0.2$ & \\
\hline \multirow{2}{*}{$\left(\mathrm{CH}_{3} \mathrm{OH}\right) \mathrm{Sn}^{\mathrm{V}}(\mathrm{OSi} \equiv)_{4}$} & Strong & -588 & $375 \pm 35$ & $-0.8 \pm 0.2$ & \\
\hline & Weak & -576 & $390 \pm 20$ & $-0.7 \pm 0.3$ & \\
\hline$(i-\mathrm{PrOH}) \mathrm{Sn}^{\mathrm{V}}(\mathrm{OSi} \equiv)_{4}$ & Weak & -586 & $400 \pm 25$ & $-0.8 \pm 0.2$ & \\
\hline$(i-\mathrm{BuOH}) \mathrm{Sn}^{\mathrm{V}}(\mathrm{OSi} \equiv)_{4}$ & Weak & -582 & $415 \pm 25$ & $-0.7 \pm 0.3$ & \\
\hline
\end{tabular}

${ }^{\mathrm{a}}$ Isotropic chemical shift.

${ }^{\mathrm{b}}$ Theoretical data.

${ }^{\mathrm{c}}$ Approximate values from Fig. S29 in 31.

${ }^{\mathrm{d}}$ Experimental data, 4 probe molecules per one Sn atom.

$\underline{\text { Sn-sites with weak Lewis acidity (-443 ppm) }}$

The major fraction of sites, corresponding to approximately $\sim 85 \%$ of the $\mathrm{Sn}$ sites in the samples studied (Fig. 1), is characterized by relatively weak Lewis acidity. The adsorption of acetonitrile and alcohols over these sites reveals that $\mathrm{Sn}$ atoms change their coordination and become pentacoordinated (Fig. 3), which accounts for the adsorption of one probe molecule per tin site in accordance with other reports ${ }^{18,20}$. Acetonitrile show very weak adsorption over these Sn-sites. The position of $\mathrm{Sn}$ signal is changing from -480 to $-570 \mathrm{ppm}$ upon variation of $\mathrm{CH}_{3} \mathrm{CN}$ loadings from 0.5 to 4 molecules per Sn site (Fig. 2), which points to fast exchange between different adsorption sites, related and not related to tin. The alcohol molecules show stronger interaction with $\mathrm{Sn}$ sites, the exchange process is not detected and the signal at ca. $-570 \mathrm{ppm}$ appears already at low loadings (Fig. 3b). The analysis of the chemical shifts and parameters of NMR line shape of the signal at ca. -580 ppm, observed for all adsorbates (Table 1) point to 
similar features for acetonitrile and alcohols at higher loadings. We therefore conclude that the structure of adsorption complexes is similar in all the cases.

A different situation is observed in the case of water adsorption. At the early steps of the interaction with water, the Sn-sites responsible for the NMR signal at $-443 \mathrm{ppm}$ adsorb one molecule of water leading to the formation of pentacoordinated $\mathrm{Sn}$ as confirmed by the appearance of the line at ca. $-581 \mathrm{ppm}$. However, after several hours pentacoordinated Sn-sites start to convert into hexacoordinated sites. This transformation is slow and kinetically limited. The complete transformation requires more than 3 weeks, which is in line with the results obtained by Courtney et al. ${ }^{17}$, who showed that adsorption of water is accompanied by the rupture of $\mathrm{Si}-\mathrm{O}-\mathrm{Sn}$ bond and formation of $\mathrm{SiOH}$ groups. These $\mathrm{SiOH}$ groups were shown to be slightly acidic and exchangeable with alkali cations ${ }^{19}$. Furthermore, this work points to the formation of $\mathrm{SnOH}$ as confirmed by CP-CPMG MAS NMR spectra showing the intensive signal for hexacoordinated Sn at ca. -689 ppm (Fig. S4). Putting together our results with the literature data $^{17,19}$ one can conclude that the observation of hexacoordinated Sn-sites is due to dissociative adsorption of water over these sites:
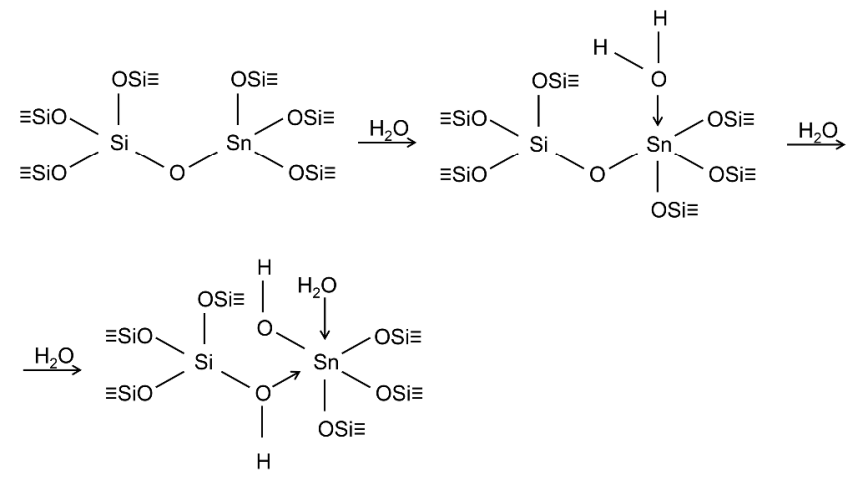

Scheme 1. Dissociative adsorption of water over tin sites in Sn-BEA. 
During this process the rupture of Si-O-Sn bonds occurs and the Sn-site becomes more flexible and able to accommodate additional water molecule leading to the observation of hexacoordinated tin.

The hydrolysis of Si-O-Sn bonds explains why the formation of 6-coordinated tin is observed only in the case of adsorption of water and not in the case of acetonitrile and alcohols. One can suppose that tin is not stable in the octahedral surrounding in the zeolite framework due to steric hindrance. Consequently, high energy is required to transform rather stable distorted pentacoordinated tin into hexacoordinated tin. The dissociative adsorption of water is slow over weak Sn-sites at ambient temperature and mild relative humidity, but it can be accelerated when the temperature is raised and the humidity increased ${ }^{17}$.

\section{$\underline{\text { Sn-sites with strong Lewis acidity }(-422 \mathrm{ppm})}$}

Monitoring the fate of the signal at ca. $-422 \mathrm{ppm}$ during the adsorption of different probe molecules points to a stronger interaction with these sites compared to those observed at ca. -443 ppm. In the case of acetonitrile, even very small loadings give the line at ca. -580 ppm, corresponding to pentacoordinated Sn (Fig. 2). No exchange process with other sites is observed, pointing to strong adsorption over the. $-422 \mathrm{ppm}$ sites. Furthermore, the dissociative adsorption of water occurs in a few hours over -422 ppm Sn-sites at ambient temperature (Fig. 4), whereas it requires several weeks in the case of -443 ppm sites. Finally, secondary alcohols (isopropanol and isobutanol) reveal the formation of hexacoordinated tin upon the adsorption over $-422 \mathrm{ppm}$ Sn-sites at high loadings (Fig. 3), whereas only pentacoordinated tin was observed in the case of -443 ppm Sn-sites.

The latter observation requires additional discussion. As it has been shown above, the formation of hexacoordinated Sn-sites is an activated process and requires the rupture of Si-O-Sn 
bonds. In the case of interaction with secondary alcohols, this rupture can take place via dissociative adsorption and formation of alkoxy groups attached to silicon atoms and $\mathrm{Sn}-\mathrm{OH}$ groups:
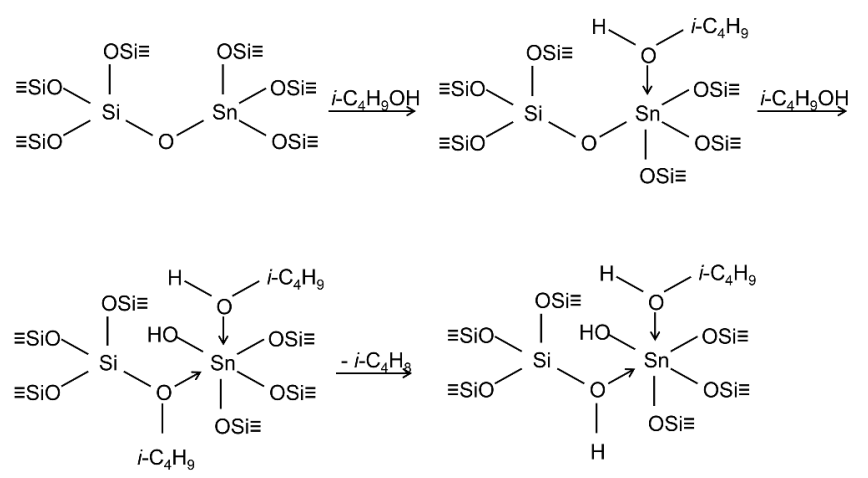

Scheme 2. Dissociative adsorption of isobutanol over tin sites in Sn-BEA.

The alkoxy groups can further decompose into corresponding olefin and Si-OH group. Another possibility involves dehydration of secondary alcohols over Sn-sites yielding an olefin and water and dissociative adsorption of water over Sn-site:
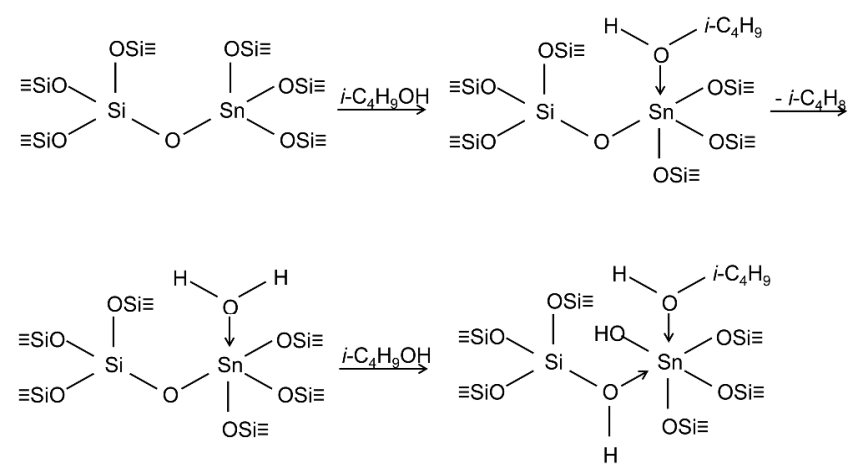

Scheme 3. Dehydration of isobutanol over tin site in Sn-BEA followed by dissociative adsorption of water formed.

The decomposition of alcohols into olefins and water over Sn-sites has been observed previously $^{20}$. Roy et al. observed dissociative adsorption of 2-methyl-2-propanol over Sn-BEA leading to evolution of butene and water during TPD-TGA experiments. The amount of butene and water desorbed was close to Sn content in the sample. Our results confirm this findings but 
suggest that only Sn sites with strong Lewis acid strength (-422 ppm) are involved in this type of interaction at ambient temperature. One can speculate that at higher temperature, weaker tin sites can also be involved in this interaction.

It should be noted that the present data as well as the literature data ${ }^{17}$ do not allow to distinguish between two possible pathways: 1) dissociative adsorption of alcohols (Scheme 2) or 2) dehydration of alcohols / dissociative adsorption of water (Scheme 3). Further experiments are needed to verify this.

The results obtained are useful for understanding the effect of solvents on the catalytic properties, since they clearly demonstrate that the chosen solvent can modify the active Sn-site even at moderate temperatures. As most reactions involving Sn-BEA and the conversion of sugar substrates are currently being performed in either water or using smaller alcohol solvents (methanol, ethanol), the current study shows that it is difficult to investigate the system without taking into account interaction with the solvent. Additionally, as it is shown here that water even at ambient temperature will modify the catalyst, this naturally has relevance for the catalytic system, as also pointed out by Corma et $a l .{ }^{43}$, since age and general history of the tested Sn-BEA are often not reported.

\section{CONCLUSIONS}

Probing of Sn-sites in Sn-BEA by ${ }^{119} \mathrm{Sn}$ CPMG MAS NMR of adsorbed acetonitrile, methanol, isopropanol, isobutanol and water reveals two sites with different adsorption properties: 1) Snsites with strong Lewis acidity, characterized by the NMR line at ca. -422 ppm in dehydrated state; and 2) Sn-sites with lower Lewis acidity at $-443 \mathrm{ppm}$. In the samples studied, the major fraction of Sn-sites $(\sim 85 \%)$ could be attributed to the latter. 
Interaction of both tin sites with acetonitrile and methanol leads to formation of only pentacoordinated tin species, which is confirmed by the appearance of two well-defined NMR signals at ca. -570 and -594 ppm corresponding to the sites responsible for the -443 and -422 ppm signals, respectively. Observation of pentacoordinated species accounts for the formation of 1:1 adsorption complexes. Acetonitrile shows weak adsorption especially over Sn-sites, characterized by NMR signal at ca. $-443 \mathrm{ppm}$. The position of the NMR signal is found to vary from -480 to -570 ppm upon changing of $\mathrm{CH}_{3} \mathrm{CN}$ loadings from 0.5 to 4 molecules per $\mathrm{Sn}$ site, which points to fast exchange between different adsorption sites, related and not related to tin. This exchange process is not observed for the signal at $-422 \mathrm{ppm}$, pointing to stronger adsorption over this site. Analysis of chemical shifts and the NMR line shape shows similar local surroundings of the adsorbed pentacoordinated tin complexes for the different probe molecules.

Interaction of tin sites with water initially leads to the formation of pentacoordinated tin. But unlike for acetonitrile and methanol, water enables the transformation of tin sites into hexacoordinated state, evidenced by the observation of the NMR lines at ca. -689 and -703 ppm. This transformation occurs at ambient temperatures in several hours in the case of the strong sites $(-422 \mathrm{ppm})$, but requires several weeks for weak sites $(-443 \mathrm{ppm})$, indicating that the process is kinetically limited by the chemical interaction. We suggest that the formation of hexacoordinated tin is a result of the hydrolysis of Si-O-Sn bonds, occurring already at ambient temperatures.

Interaction with isopropanol and isobutanol shows the formation of pentacoordinated $\mathrm{Sn}$ species over weak sites and hexacoordinated Sn over strong sites, pointing to the possibility of dissociative adsorption of secondary alcohols over the Sn-sites with strong Lewis acidity. 
The results obtained could have practical implications in understanding the effect of solvents on the catalytic properties, since they clearly demonstrate that solvents can modify the active Snsite. 


\section{ASSOCIATED CONTENT}

Supporting Information. Details of preparation and characterization of Sn-BEA, main acquisition parameters in NMR spectra, XRD and SEM images of the product obtained, ${ }^{119} \mathrm{Sn}$ DP- and CP-CPMG/MAS NMR spectra of hydrated and dehydrated samples. This material is available free of charge via the Internet at http://pubs.acs.org.

\section{AUTHOR INFORMATION}

\section{Corresponding Author}

*Irina I. Ivanova

Laboratory of kinetics and catalysis, Department of Chemistry, Lomonosov MSU

119991, Moscow, Leninskie gory, 1 bld. 3.

Tel.: +7(495)939-35-70

e-mail: IIIvanova@phys.chem.msu.ru

\section{Author Contributions}

The manuscript was written through contributions of all authors. All authors contributed equally.

\section{ACKNOWLEDGMENT}

The authors thank the Russian Science Foundation for the financial support (grant 14-2300094). Alexander V. Yakimov gratefully acknowledges Haldor Topsøe A/S for a PhD fellowship. Søren Tolborg is funded by the Bio-Value platform under the Danish Council for 
Strategic Research and The Danish Council for Technology and Innovation (Case no. 060300522B).

\section{ABBREVIATIONS}

DNP, dynamic nuclear polarization; CPMG, sequence containing a number of refocusing pulses developed by Carr-Purcell-Meiboom-Gill; CP-CPMG, cross-polarization sequence combined with CPMG echo train acquisition; DP-CPMG, direct polarization (90 ${ }^{\circ}$-pulse) combined with CPMG echo train acquisition. 


\section{REFERENCES}

(1) Holm, M. S.; Saravanamurugan, S.; Taarning E. Conversion of sugars to lactic acid derivatives using heterogeneous zeotype catalysts. Science 2010, 328, 602-605.

(2) Osmundsen, C. M.; Holm, M. S.; Dahl, S.; Taarning, E. Tin-containing silicates: structure-activity relations. Proc. R. Soc. A 2012, 468, 2000-2016.

(3) Moliner, M.; Román-Leshkov, Y.; Davis, M. E. Tin-containing zeolites are highly active catalysts for the isomerization of glucose in water. Proc. Natl. Acad. Sci. U. S. A. 2010, 107, 6164-6168.

(4) Román-Leshkov, Y.; Moliner, M.; Labinger, J.; Davis, M. E. Mechanism of glucose isomerization using a solid Lewis acid catalyst in water. Angew. Chem., Int. Ed. 2010, 49, 8954-8957.

(5) Bermejo-Deval, R.; Assary, R. S.; Nikolla, E.; Moliner, M.; Román-Leshkov, Y.; Hwang, S.-J.; Palsdottir, A.; Silverman, D.; Lobo, R. F.; Curtiss, L. A. et al. Metalloenzyme-like catalyzed isomerizations of sugars by Lewis acid zeolites. Proc. Natl. Acad. Sci. U. S. A. 2012, 109, 9727-9732.

(6) Corma, A.; Nemeth, L. T.; Renz, M.; Valencia, S. Sn-zeolite beta as a heterogeneous chemoselective catalyst for Baeyer-Villiger oxidations. Nature. 2001, 412, 423-425.

(7) Renz, M.; Blasco, T.; Corma, A.; Fornes, V.; Jensen, R.; Nemeth, L. Selective and shape-selective Baeyer-Villiger oxidations of aromatic aldehydes and cyclic ketones with Sn-beta zeolites and H2O2. Chem. - Eur. J. 2002, 8, 4708-4717. 
(8) Corma, A.; Domine, M. E.; Valencia, S. Water-resistant solid Lewis acid catalysts: Meerwein-Ponndorf-Verley and Oppenauer reactions catalyzed by tin-beta zeolite. $J$. Catal. 2003, 215, 294-304.

(9) Tang, B.; Dai, W.; Wu, G.; Guan, N.; Li, L.; Hunger M. Improved postsynthesis strategy to Sn-beta zeolites as Lewis acid catalysts for the ring-opening hydration of epoxides. ACS Catal. 2014, 4, 2801-2810.

(10) Dapsens, P. Y.; Mondelli, C.; Perez-Ramirez, J. Design of Lewis-acid centres in zeolitic matrices for the conversion of renewables. Chem. Soc. Rev. 2015, 44, 7025-7043.

(11) Luo, H. Y.; Lewis, J. D.; Roman-Leshkov Y. Lewis acid zeolites for biomass conversion: Perspectives and challenges on reactivity, synthesis, and stability. Annu. Rev. Chem. Biomol. Eng. 2016, 7, 663-639.

(12) Boronat, M.; Concepción, P.; Corma, A.; Renz, M.; Valencia S. Determination of the catalytically active oxidation Lewis acid sites in Sn-beta zeolites, and their optimisation by the combination of theoretical and experimental studies. J. Catal. 2005, 234, 111118.

(13) Li, Y.-P.; Head-Gordon, M.; Bell A. T. Analysis of the reaction mechanism and catalytic activity of metal-substituted beta zeolite for the isomerization of glucose to fructose. ACS Catal. 2014, 4, 1537-1545.

(14) Kulkarni, B. S.; Krishnamurty, S.; Pal, S. Probing Lewis acidity and reactivity of Snand Ti-beta zeolite using industrially important moieties: A periodic density functional study. J. Mol. Catal. A: Chem. 2010, 329, 36-43. 
(15) Rai, N.; Caratzoulas, S.; Vlachos, D. G. Role of silanol group in Sn-beta zeolite for glucose isomerization and epimerization reactions. ACS Catal. 2013, 3, 2294-2298.

(16) Yang, G.; Pidko, E. A.; Hensen E. J. M. Structure, stability, and Lewis acidity of mono and double $\mathrm{Ti}, \mathrm{Zr}$, and $\mathrm{Sn}$ framework substitutions in BEA zeolites: A periodic density functional theory study. J. Phys. Chem. C 2013, 117, 3976-3986.

(17) Courtney, T. D.; Chang, C.-C.; Gorte, R. J.; Lobo, R. F.; Fan, W.; Nikolakis, V. Effect of water treatment on Sn-BEA zeolite: Origin of $960 \mathrm{~cm}-1$ FTIR peak. Microporous Mesoporous Mater. 2015, 210, 69-76.

(18) Harris, J. W.; Cordon, M. J.; Di Iorio, J. R.; Vega-Vila, J. C.; Ribeiro, F. H.; Gounder, R. Titration and quantification of open and closed Lewis acid sites in Sn-beta zeolites that catalyze glucose isomerization. J. Catal. 2016, 335, 141-154.

(19) Otomo, R.; Kosugi, R.; Kamiya, Y.; Tatsumia T.; Yokoi, T. Modification of Sn-beta zeolite: Characterization of acidic/basic properties and catalytic performance in BaeyerVilliger oxidation. Catal. Sci. Technol. 2016, 6, 2787-2795.

(20) Roy, S.; Bakhmutsky, K.; Mahmoud, E.; Lobo, R. F.; Gorte, R. J. Probing Lewis acid sites in Sn-beta zeolite. ACS Catal. 2013, 3, 573-580.

(21) Wolf, P.; Valla, M.; Rossini, A. J.; Comas-Vives, A.; Nunez-Zarur, F.; Malaman, B.; Lesage, A.; Emsley, L.; Coperet, C.; Hermans, I. NMR signatures of the active sites in Sn- $\beta$ zeolite. Angew. Chem., Int. Ed. 2014, 53, 10179 -10183. 
(22) Gunther, W. R., Michaelis V. K.; Caporini, M. A.; Griffin, R. G.; Román-Leshkov, Y. Dynamic nuclear polarization NMR enables the analysis of Sn-beta zeolite prepared with natural abundance 119Sn precursors. J. Am. Chem. Soc. 2014, 136, 6219-6222.

(23) Hwang, S-J.; Gounder, R.; Bhawe, Y.; Orazov, M.; Bermejo-Deval, R.; Davis, M. E. Solid state NMR characterization of Sn-beta zeolites that catalyze glucose isomerization and epimerization. Top. Catal. 2015, 58, 435-440.

(24) Kolyagin, Y. G.; Yakimov, A. V.; Tolborg, S.; Vennestrøm, P. N. R.; Ivanova, I. I. Application of ${ }^{119} \mathrm{Sn}$ CPMG MAS NMR for fast characterization of Sn sites in zeolites with natural ${ }^{119} \mathrm{Sn}$ isotope abundance, J. Phys. Chem. Lett. 2016, 7, 1249-1253.

(25) Gunther, W. R.; Michaelis, V. K.; Griffin, R. G.; Román-Leshkov, Y. Interrogating the Lewis acidity of metal sites in beta zeolites with $15 \mathrm{~N}$ pyridine adsorption coupled with MAS NMR spectroscopy. J. Phys. Chem. C 2016, in press, DOI: 10.1021/acs.jpcc.6b07811.

(26) Bermejo-Deval, R.; Gounder, R.; Davis, M. E. Framework and extraframework tin sites in zeolite beta react glucose differently. ACS Catal. 2012, 2, 2705-2713.

(27) Gounder, R.; Davis, M. E. Beyond shape selective catalysis with zeolites: hydrophobic void spaces in zeolites enable catalysis in liquid water. AIChE J. 2013, 59, 3349-3358.

(28) Boronat, M.; Concepción, P.; Corma, A.; Renz, M. Peculiarities of Sn-beta and potential industrial applications. Catal. Today. 2007, 121, 39-44.

(29) Boronat, M.; Concepción, P.; Corma, A.; Navarro, M. T.; Renz, M.; Valencia, S. Reactivity in the confined spaces of zeolites: The interplay between spectroscopy and 
theory to develop structure-activity relationships for catalysis. Phys. Chem. Chem. Phys. 2009, 11, 2876-2884.

(30) Corma, A.; Domine, M. E; Nemeth, L.; Valencia, S. Al-free Sn-beta zeolite as a catalyst for the selective reduction of carbonyl compounds (Meerwein-Ponndorf-Verley reaction). J. Am. Chem. Soc. 2002, 124, 3194-3195.

(31) Wolf, P.; Valla, M.; Nunez-Zarur, F.; Comas-Vives, A.; Rossini, A. J.; Firth, C.; Kallas, H.; Lesage, A.; Emsley, L.; Copéret, C. et al. Correlating synthetic methods, morphology, atomic-level structure, and catalytic activity of Sn- $\beta$ catalysts. ACS Catal. 2016, 6, 4047-4063.

(32) Lewis, J. D.; Van de Vyver, S.; Crisci, A. J.; Gunther, W. R.; Michaelis, V. K.; Griffin, R. G.; Román-Leshkov, Y. A continuous flow strategy for the coupled transfer hydrogenation and etherification of 5-(hydroxymethyl)furfural using Lewis acid zeolites. ChemSusChem 2014, 7, 2255 - 2265.

(33) Bermejo-Deval, R.; Orazov, M.; Gounder, R.; Hwang, S-J.; Davis, M. E. Active sites in Sn-beta for glucose isomerization to fructose and epimerization to mannose. ACS Catal. 2014, 4, 2288-2297.

(34) Tolborg, S.; Katerinopoulou, A.; Falcone, D. D.; Sádaba, I.; Osmundsen, C. M.; Davis, R. J.; Taarning, E.; Fristrup P.; Holm, M. S. Incorporation of tin affects crystallization, morphology, and crystal composition of Sn-beta. J. Mater. Chem. A 2014, 2, 2025220262. 
(35) Yakimov, A. V.; Kolyagin, Y. G.; Tolborg, S.; Vennestrøm, P. N. R.; Ivanova, I. I. Accelerated synthesis of Sn-BEA in fluoride media: Effect of H2O content in the gel. New J. Chem. 2016, 40, 4367-4374.

(36) Chaudhari, K.; Das, T. K.; Rajmohanan, P. R.; Lazar, K.; Sivasanker, S.; Chandwadkar, A. J. Synthesis, characterization, and catalytic properties of mesoporous tin-containing analogs of MCM-41. J. Catal. 1999, 183, 281-291.

(37) Massiot, D.; Fayon, F.; Capron, M.; King, I.; Le Calve, S.; Alonso, B.; Durand, J.-O.; Bujoli, B.; Gan, Z.; Hoatson, G. Modelling one- and two-dimensional solid-state NMR spectra. Magn. Reson. Chem. 2002, 40, 70-76.

(38) Hammond, C.; Padovan, D.; Al-Nayili, A.; Wells, P. P.; Gibson, E. K.; Dimitratos N. Identification of active and spectator $\mathrm{Sn}$ sites in $\mathrm{Sn}-\beta$ following solid-state stannation, and consequences for Lewis acid catalysis. ChemCatChem 2015, 7, 3322 - 3331.

(39) Bain A. D. Chemical exchange in NMR. Prog. Nucl. Magn. Reson. Spectrosc. 2003, 43, 63-103.

(40) Taarning, E.; Saravanamurugan, S.; Holm, M. S.; Xiong, J.; West, R. M.; Christensen, C. H. Zeolite-catalyzed isomerization of triose sugars. ChemSusChem 2009, 2, 625-627.

(41) Gunther, W. R.; Wang, Y.; Ji, Y.; Michaelis, V. K.; Hunt, S. T.; Griffin, R. G.; RománLeshkov, Y. Sn-beta zeolites with borate salts catalyse the epimerization of carbohydrates via an intramolecular carbon shift. Nat. Commun. 2012, 3, 1109.

(42) Tolborg, S.; Meier, S.; Sádaba, I.; Elliot, S. G.; Kristensen, S. K.; Shunmugavel, S., Riisager, A.; Fristrup, P.; Skrydstrup, T.; Taarning, E. Tin-containing silicates: 
Identification of a glycolytic pathway via 3-deoxyglucosone. Green Chem. 2016, 18, 3360-3369.

(43) Boronat, M.; Corma, A.; Michael, R. Catalysis by Lewis acids: Basic Principles for Highly Stereoselective Heterogeneously Catalyzed Cyclization Reactions in Turning Points in Solid-State, Materials and Surface Science: A Book in Celebration of the Life and Work of Sir John Meurig Thomas; Harris, K. D. M., Edwards, P. P., Eds.; Royal Society of Chemistry: U.K., 2007. 
TOC Graphic

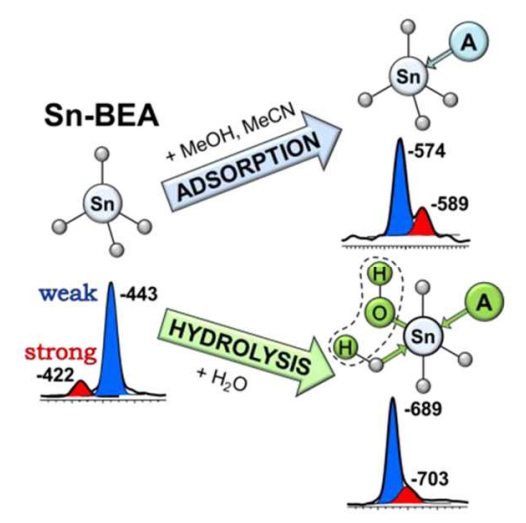

20

21

22

23

24

25

26

27

28

29

30

31

32

33

34

35

36

37

38

39

40

41

42

43

44

45

46

47

48

49

50

51

52

53

54

55

56

57

58

59

60

ACS Paragon Plus Environment 


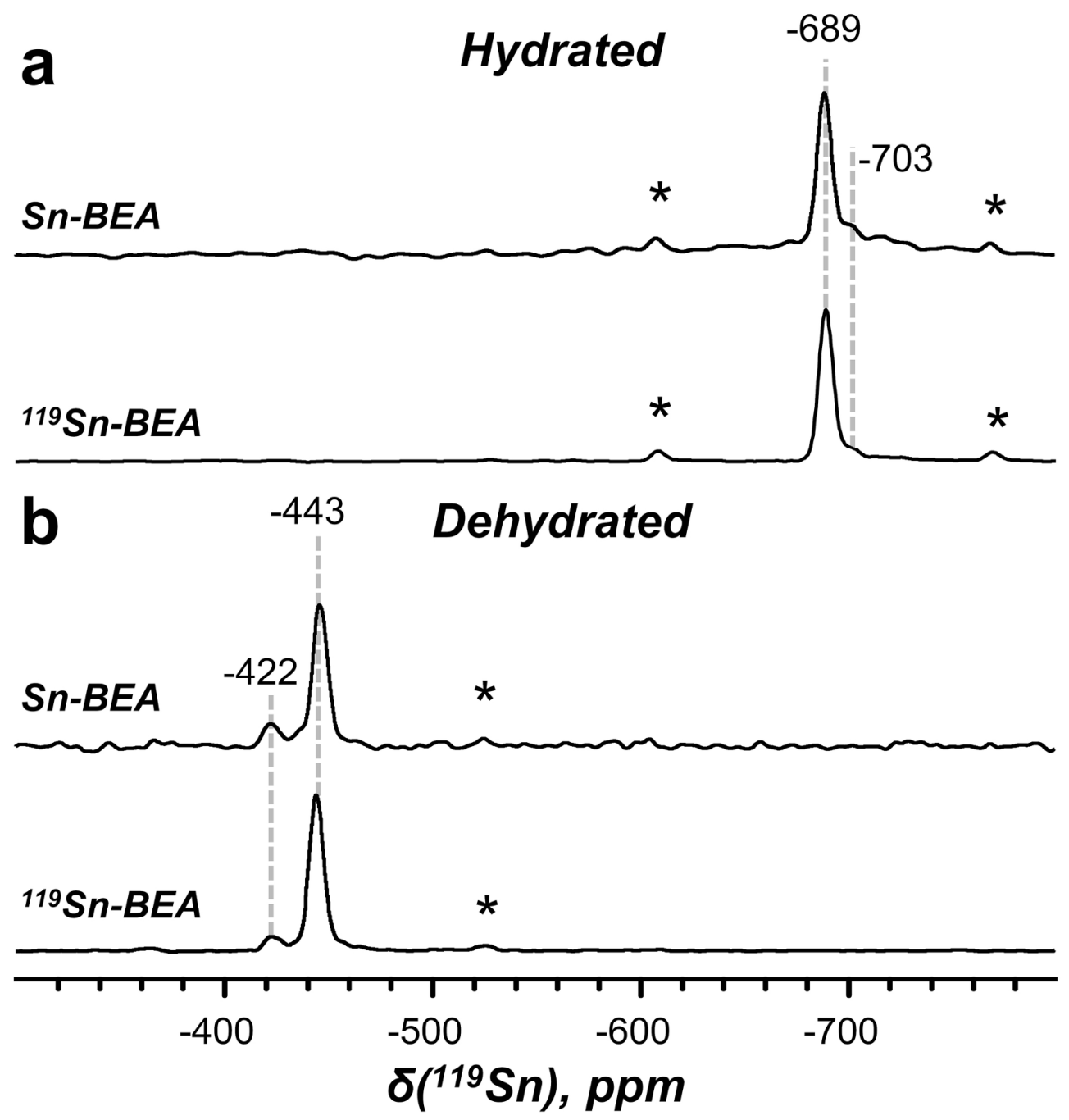

Fig. 1

$91 \times 97 \mathrm{~mm}(600 \times 600 \mathrm{DPI})$ 
a
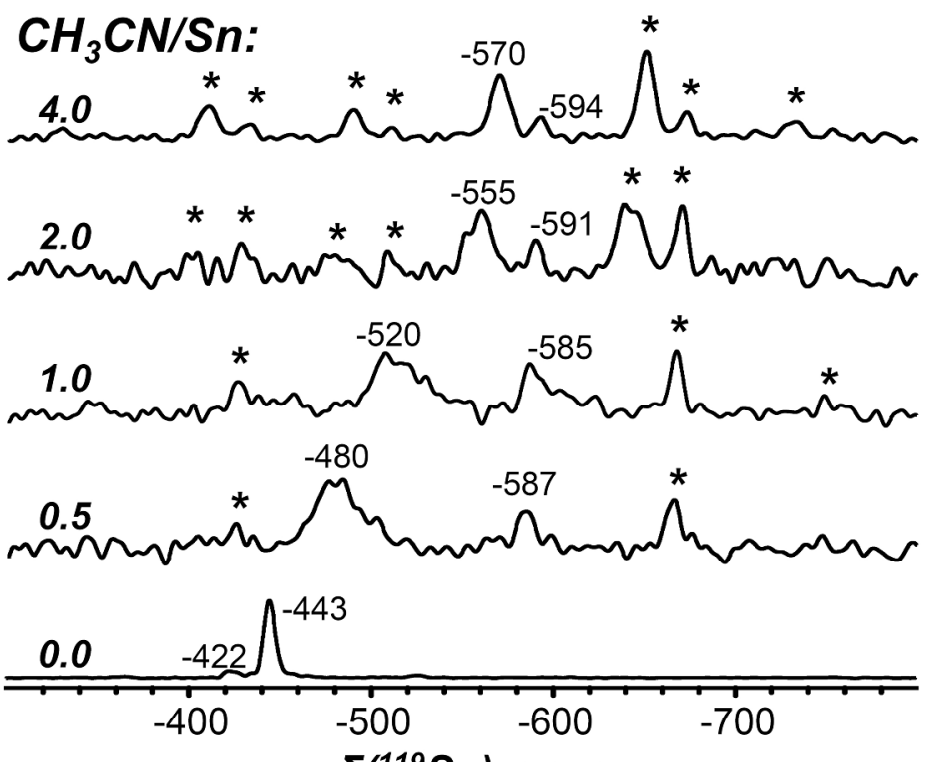

b

$\delta\left({ }^{119} \mathrm{Sn}\right), \mathrm{ppm}$

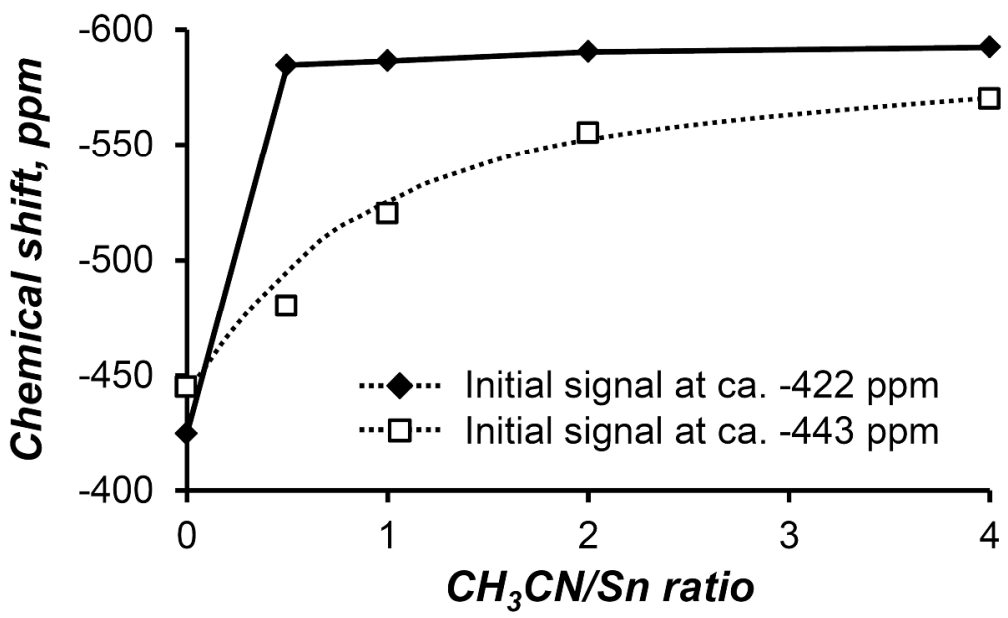

$124 \times 183 \mathrm{~mm}(600 \times 600 \mathrm{DPI})$ 
a
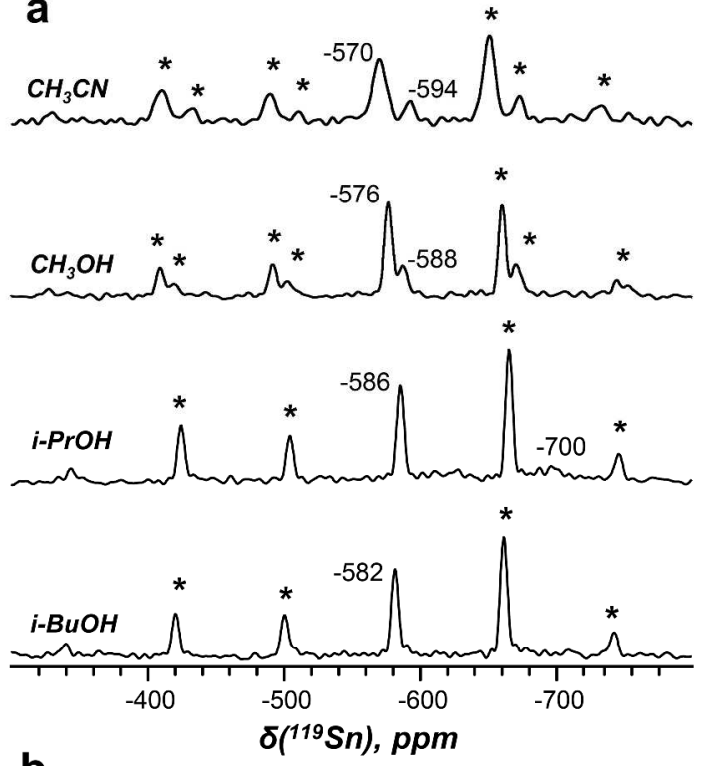

b
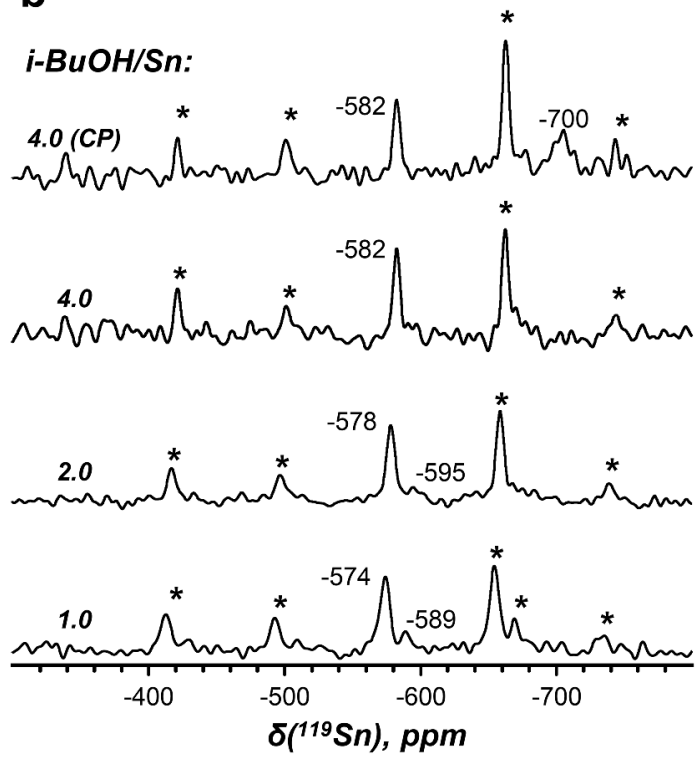

$188 \times 416 \mathrm{~mm}(600 \times 600 \mathrm{DPI})$ 
a 


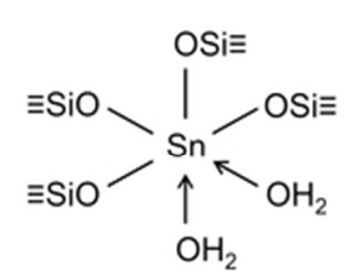

(I)

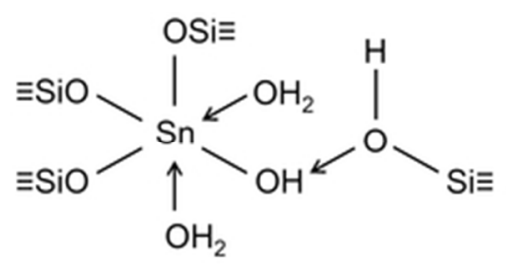

(II)<smiles></smiles>

(III)

$25 \times 7 \mathrm{~mm}(600 \times 600 \mathrm{DPI})$

21

22

23

24

25

26

27

28

29

30

31

32

33

34

35

36

37

38

39

40

41

42

43

44

45

46

47

48

49

50

51

52

53

54

55

56

57

58

59

60 


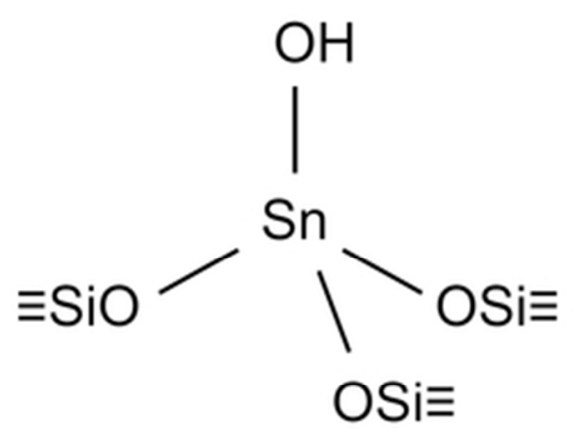

(IV)

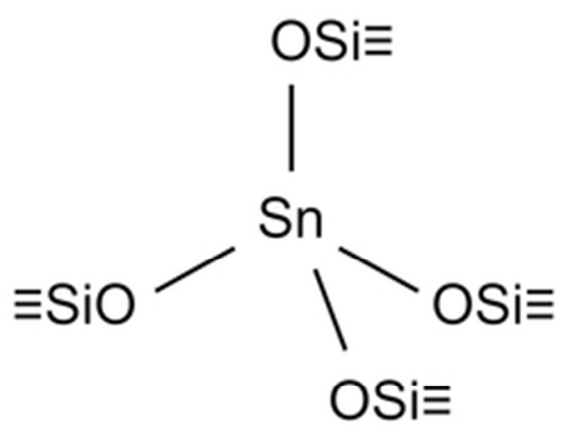

(V)

$24 \times 11 \mathrm{~mm}(600 \times 600$ DPI $)$ 
1

2

3

4

5

6

7

8

9

10

11

12

13

14

15

16

17

18

19

20

21

22

23

24

25

26

27

28

29

30

31

32

33

34

35

36

37

38

39

40

41

42

43

44

45

46

47

48

49

50

51

52

53

54

55

56

57

58

59

60
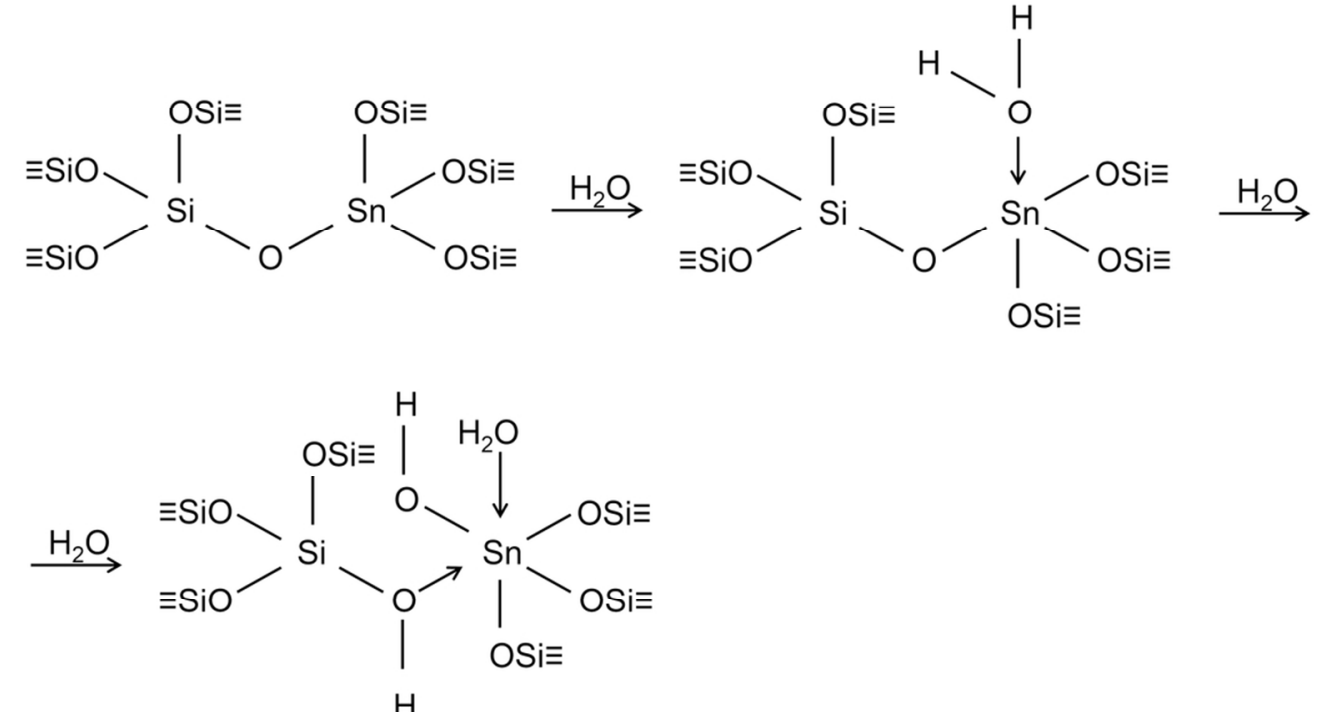

$48 \times 27 \mathrm{~mm}(600 \times 600 \mathrm{DPI})$ 


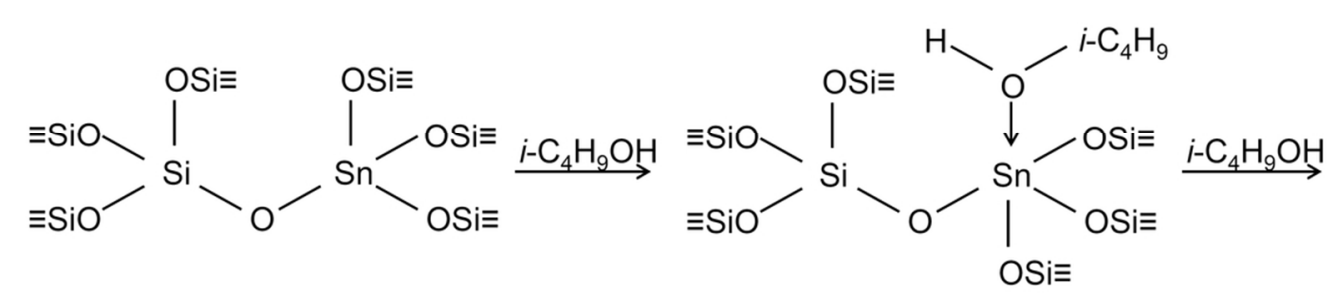

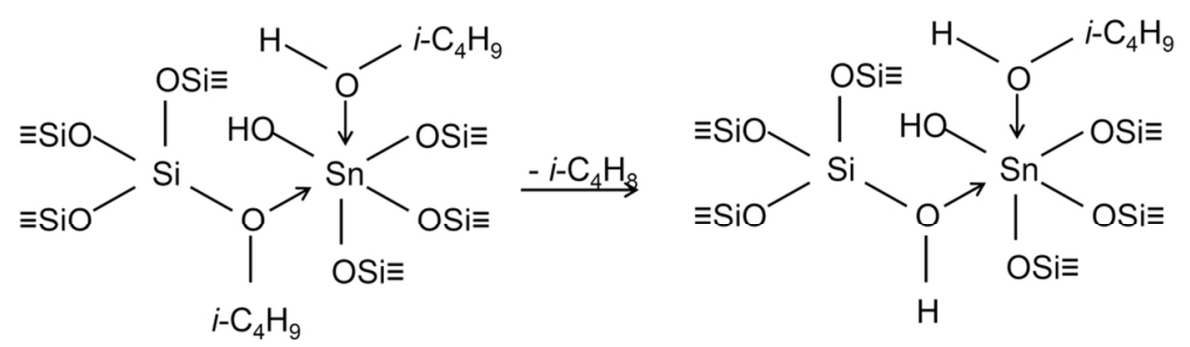

$47 \times 26 \mathrm{~mm}(600 \times 600$ DPI $)$ 
1

2

3

4

5

6

7

8

9

10

11

12

13

14

15

16

17

18

19

20

21

22

23

24

25

26

27

28

29

30

31

32

33

34

35

36

37

38

39

40

41

42

43

44

45

46

47

48

49

50

51

52

53

54

55

56

57

58

59

60
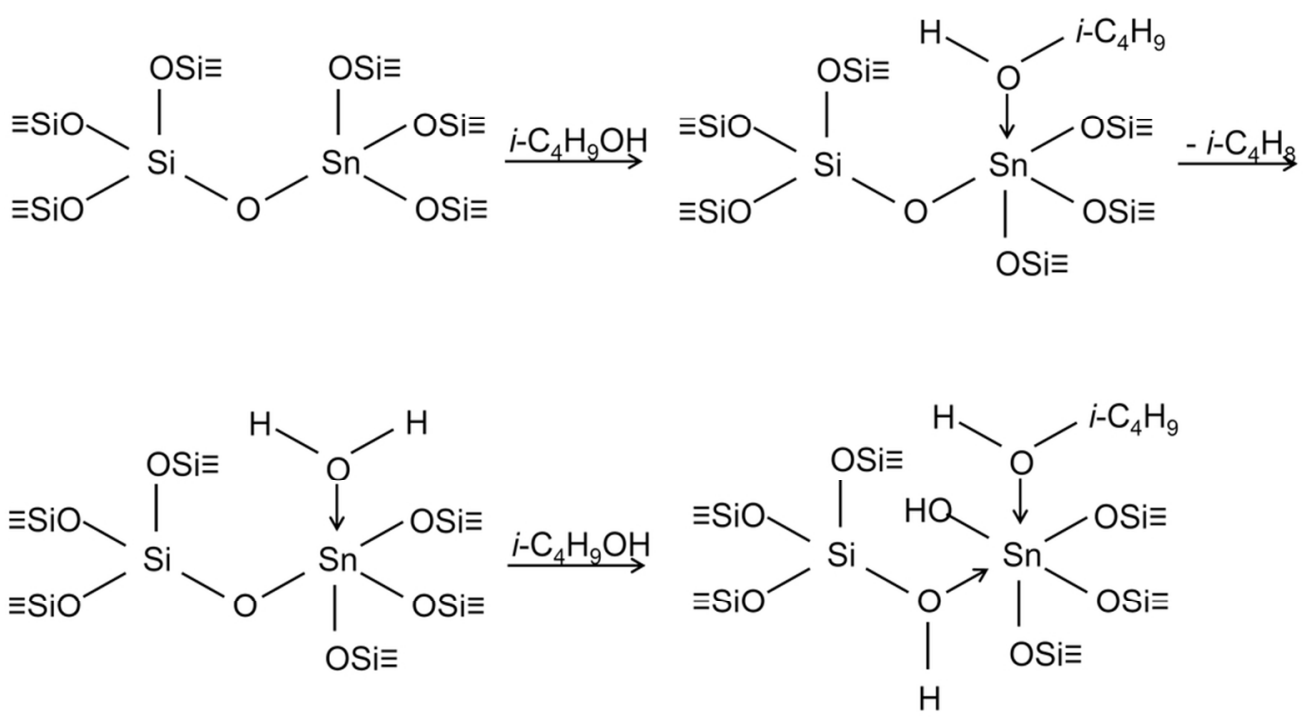

$47 \times 26 \mathrm{~mm}(600 \times 600 \mathrm{DPI})$ 


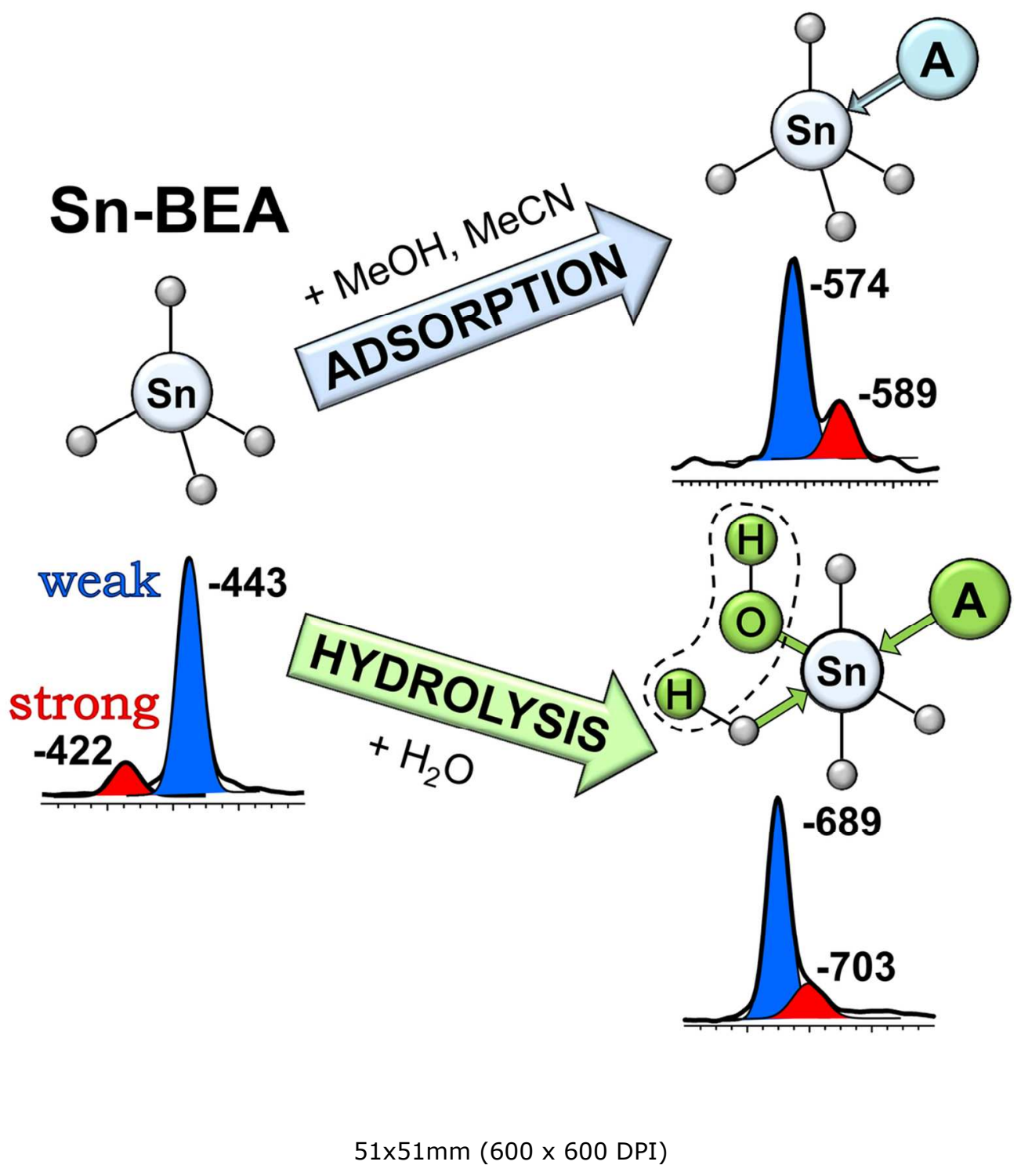

